\title{
Review
}

\section{Asymmetric autocatalysis. Chiral symmetry breaking and the origins of homochirality of organic molecules}

\author{
By Kenso SoA ${ }^{* 1, \dagger}$ \\ (Communicated by Kenji MORI, M.J.A.)
}

\begin{abstract}
Biological homochirality, such as that of L-amino acids, has been a puzzle with regards to the chemical origin of life. Asymmetric autocatalysis is a reaction in which a chiral product acts as an asymmetric catalyst to produce more of itself in the same absolute configuration. 5-Pyrimidyl alkanol was found to act as an asymmetric autocatalyst in the enantioselective addition of diisopropylzinc to pyrimidine-5-carbaldehyde. Asymmetric autocatalysis of 2-alkynyl-5pyrimidyl alkanol with an extremely low enantiomeric excess of $c a .0 .00005 \%$ exhibited significant asymmetric amplification to afford the same pyrimidyl alkanol with $>99.5 \%$ enantiomeric excess and with an increase in the quantity of the same compound. We have employed asymmetric autocatalysis to examine the origin of homochirality. Asymmetric autocatalysis triggered by circularly polarized light, chiral minerals such as quartz, chiral organic crystals composed of achiral compounds gave highly enantioenriched pyrimidyl alkanol with absolute configurations corresponding with those of the chiral triggers. Absolute asymmetric synthesis without the intervention of any chiral factor was achieved. Chiral isotopomers acted as chiral triggers of asymmetric autocatalysis.
\end{abstract}

Keywords: asymmetric autocatalysis, origin of homochirality, amplification of chirality, absolute asymmetric synthesis, symmetry breaking, chirality

\section{Introduction}

Two of the characteristic features of life are the ability of self-replication and the overwhelming onehandedness of its components.

Most of the essential organic compounds composing life on Earth exist as one of two enantiomers, such as L-amino acids and D-sugars (Fig. 1a). LAmino acid and D-amino acid are mirror images of each other and not superimposable. This relation is similar to that of left and right hands. This asymmetry is called chirality. When a carbon atom has four different substituents, it becomes asymmetric (stereogenic), enabling the compound to be chiral (Fig. 1b). Since all living creatures on Earth employ the same chirality as that of L-amino acids and Dsugars, this is called biological homochirality. Bio-

*1 Department of Applied Chemistry, Tokyo University of Science, Tokyo, Japan.

$\dagger$ Correspondence should be addressed: K. Soai, Department of Applied Chemistry, Tokyo University of Science, 1-3 Kagurazaka, Shinjuku-ku, Tokyo 162-8601, Japan (e-mail: soai@ rs.kagu.tus.ac.jp). logical homochirality is not a mere phenomenon; it is an essential prerequisite for the emergence and function of life. When two persons shake hands, it is normal for both to use his (her) right hand (homochirality). However, if one person uses his or her right hand and the other uses his or her left hand, they will be unable to shake hands with the two palms facing each other and fitting together in a firm grip. In the absence of homochirality, a similar situation would occur in biomolecules.

Proteins are formed from the condensation of Lamino acids. If D-amino acids are involved irregularly in proteins, then the structures of the proteins will change and the proteins will be unable to perform certain functions, such as enzyme functions (Fig. 1c). DNA is composed of D-deoxyribose, which is the origin of the formation of the helical structure of DNA. If L-deoxyribose is involved irregularly in DNA, the DNA helix will not be formed and genetic information will not be replicated. Thus, biological homochirality is essential for life. It should be noted that when a chiral product is formed from achiral reagents without the intervention of any chiral 
(a)

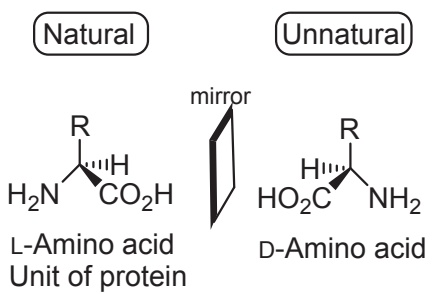

HO

Nucleoside of DNA consisting of D-deoxyribose (b) Mirror images and non-superimposable: Enantiomers, chiral molecules

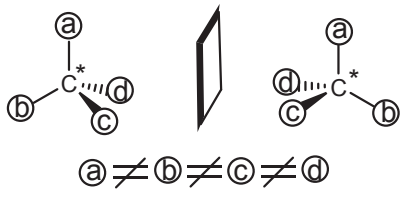

$\mathrm{C}^{*}$ : Asymmetric carbon atom

(c) Diastereomeric dipeptides of alanine

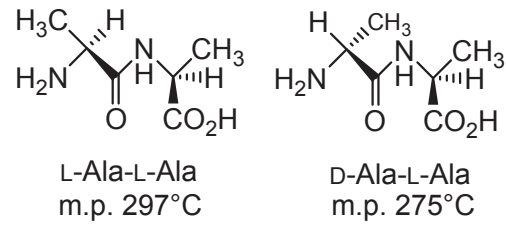

Different chemical behaviors, conformations

Fig. 1. Concepts of enantiomer, chiral molecule, asymmetric carbon. Implication of biological homochirality.

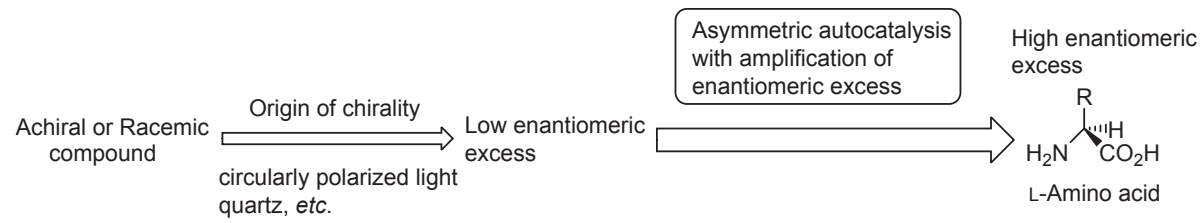

Scheme 1. A proposed route to homochirality by asymmetric autocatalysis.

factor, the newly formed chiral products are always mixtures of an equimolar amount of two enantiomers, i.e., a racemate.

Then, in the beginning, how and when did biomolecules reach the stage of homochirality before or during the emergence of life? What was the origin of chirality and what was the chemical process that led to homochirality? Ever since Pasteur revealed the molecular asymmetry of an organic compound in 1848, ${ }^{1)}$ the origin of homochirality of organic compounds has attracted considerable attention from a broad spectrum of researchers of the natural sciences.

Several theories and mechanisms such as circularly polarized light, quartz, and absolute asymmetric synthesis have been proposed in relation to the origin of the enantioenriched chirality of organic compounds. ${ }^{2-10)}$ However, in most cases, the enantiomeric excess (ee) induced by those mechanisms has been very small, and the correlation to the highly enantioenriched compounds has remained unclear. Thus, an ee amplification process is needed to reach enantiopure organic compounds (Scheme 1). ${ }^{11)-20)}$

\section{Asymmetric autocatalysis}

Asymmetric autocatalysis is a reaction in which a chiral product acts as a chiral catalyst for its own production (Scheme 2). The process is an automultiplication of the chiral molecule. Asymmetric autocatalysis has the following advantages over nonautocatalytic asymmetric catalysis: (1) the process involves automultiplication of a molecule; hence, the efficiency is high, (2) the new catalyst is produced as a product and the amount of catalyst therefore increases during the reaction; thus, the catalytic activity does not deteriorate, and (3) because the structures of the catalyst and product are identical, separation of the product from the catalyst is not required.

In 1953, Frank proposed a mechanism for asymmetric autocatalysis without mentioning any chemical structure. ${ }^{21)}$ However, no actual experimental asymmetric autocatalysis was known until our findings of asymmetric autocatalysis of pyridyl alkanol in 1990 and pyrimidyl alkanol in $1995 .{ }^{22)}$

In this review, our discovery of asymmetric autocatalysis with amplification of enantiomeric 
- Asymmetric autocatalysis

A

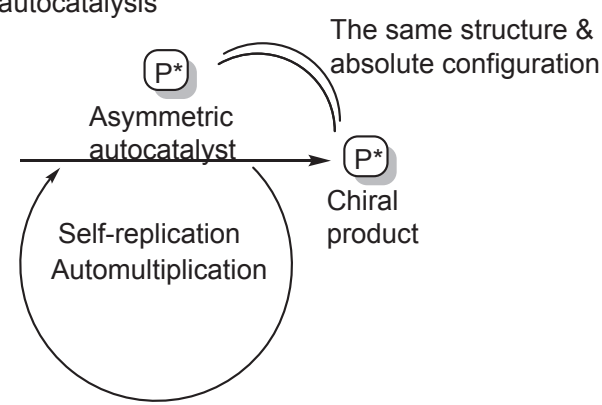

- Usual asymmetric catalysis

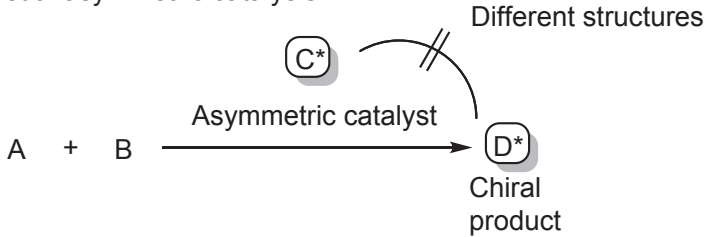

Scheme 2. The principle of asymmetric autocatalysis and comparison with usual asymmetric catalysis.

excess of pyrimidyl alkanol 1, ${ }^{22)-26)}$ multifunctionalized pyrimidyl alkanol $\mathbf{3},{ }^{27), 28)} 3$-quinolyl alkanol $\mathbf{4}^{29)-31)}$ and 5-carbamoyl-3-pyridyl alkanol $\mathbf{5}^{32), 33)}$ is described (Scheme 3). The origins of homochirality of organic compounds examined by using asymmetric autocatalysis is also described..$^{34-41)}$

2.1. Background: catalytic asymmetric addition reaction of dialkylzincs to aldehydes. Dialkylzinc reagents react with various aldehydes in the presence of chiral amino alcohols as catalysts to afford sec-alcohols with high ee. ${ }^{42), 43)}$

Pyridine-3-carbaldehyde 6, an aldehyde containing a nitrogen atom, ${ }^{44)}$ reacts faster $(1 \mathrm{~h})$ than benzaldehyde $8(16 \mathrm{~h})$ with diethylzinc $\left(\mathrm{Et}_{2} \mathrm{Zn}\right)$ to afford enantioenriched 3-pyridyl alkanol 7 in a reaction in which the same chiral catalyst, i.e., $(1 S, 2 R)-N, N$-dibutylnorephedrine (DBNE), is used (Scheme 4). ${ }^{45), 46)}$ The result showed that ethylzinc alkoxide of 3-pyridyl alkanol $\mathbf{7}$, i.e., product in situ, catalyzed the reaction.

$(S)$ - $N$-Methyldiphenylprolinol (DPMPM) catalyzes the addition of $\mathrm{Et}_{2} \mathrm{Zn}$ to aldehyde $\mathbf{8}$ to afford $(S)$-alkanol 9 with $97 \%$ ee. The catalyst $(S, S)$-threo$N$-methylphenylprolinol (PMPM) affords $(S)$-alkanol 9, while $(S, R)$-erythro-PMPM affords $(R)$-alkanol 9 (Scheme 5). ${ }^{47}$ These results show that the sense of enantioselectivity is controlled by the absolute configurations of the stereogenic centers of the alcohol moieties of the catalysts threo- and erythroPMPM.
These observations indicate that if a suitable nitrogen containing aldehyde is used, with a suitable nitrogen containing alcohol as a chiral catalyst, then the reaction with dialkylzinc might afford a chiral nitrogen containing sec-alcohol that possesses the same structure and the same absolute configuration as the catalyst. In this context, asymmetric autocatalysis is invoked.

2.2. The first asymmetric autocatalysis. $(S)$ Pyridyl alkanol 10 with $86 \%$ ee acts as an asymmetric autocatalyst in the enantioselective addition of diisopropylzinc $\left(i\right.$ - $\left.\mathrm{Pr}_{2} \mathrm{Zn}\right)$ to pyridine-3-carbaldehyde 6 to afford the same $(S)$-alkanol 10 with $35 \%$ ee (Scheme 6). ${ }^{48)}$ Although the ee of the product is lower than the original catalyst, this stands as the first example of asymmetric autocatalysis, i.e., catalytic asymmetric replication of an organic compound.

2.3. Asymmetric autocatalysis with amplification of enantiomeric excess. In 1995, we found asymmetric autocatalysis of pyrimidyl alkanol $\mathbf{1}$ with amplification of ee. (S)-Pyrimidyl alkanol 1a acts as an asymmetric autocatalyst with amplification of ee in the enantioselective addition of $i-\mathrm{Pr}_{2} \mathrm{Zn}$ to pyrimidine-5-carbaldehyde $\mathbf{2 a}$ to produce more of itself with the same absolute configuration (Scheme 3). ${ }^{22)}$ Starting from $(S)$-1a with $2 \%$ ee, the product (and the initial catalyst) was used as an asymmetric autocatalyst for the next round. The ee $(S)$-1a reached $88 \%$ after four consecutive asymmetric autocatalyses with amplification of ee.

The effect of the substituent at the 2-position of pyrimidyl alkanol $\mathbf{1}$ was examined. More significant asymmetric autocatalysis was observed with pyrimidyl alkanol 1c with alkynyl substituent at the 2-position of pyrimidine ring. When $(S)$-pyrimidyl alkanol 1c with $>99.5 \%$ ee was used as an asymmetric autocatalyst in the reaction between aldehyde 2c and $i-\mathrm{Pr}_{2} \mathrm{Zn}$, the same alkanol 1c with $>99.5 \%$ ee was obtained in $>99 \%$ yield (Scheme 7). ${ }^{24)}$ The mixture of the initial catalyst 1c and the product 1c was used as an asymmetric autocatalyst for the next round. Even after the 10th round, the catalytic reactivity (yield $>99 \%$ ) and enantioselectivity $(>99.5 \%$ ee) of alkanol 1c did not decrease. Thus, this is a practically perfect asymmetric autocatalysis of pyrimidyl alkanol 1c.

Remarkable amplification of ee was observed in the asymmetric autocatalysis of pyrimidyl alkanol 1c (Scheme 8 and Fig. 2). When it was started from an asymmetric autocatalyst 1c with an extremely low ee of $c a$. $0.00005 \%$, only three consecutive asymmetric autocatalysis reactions amplified the ee of the 

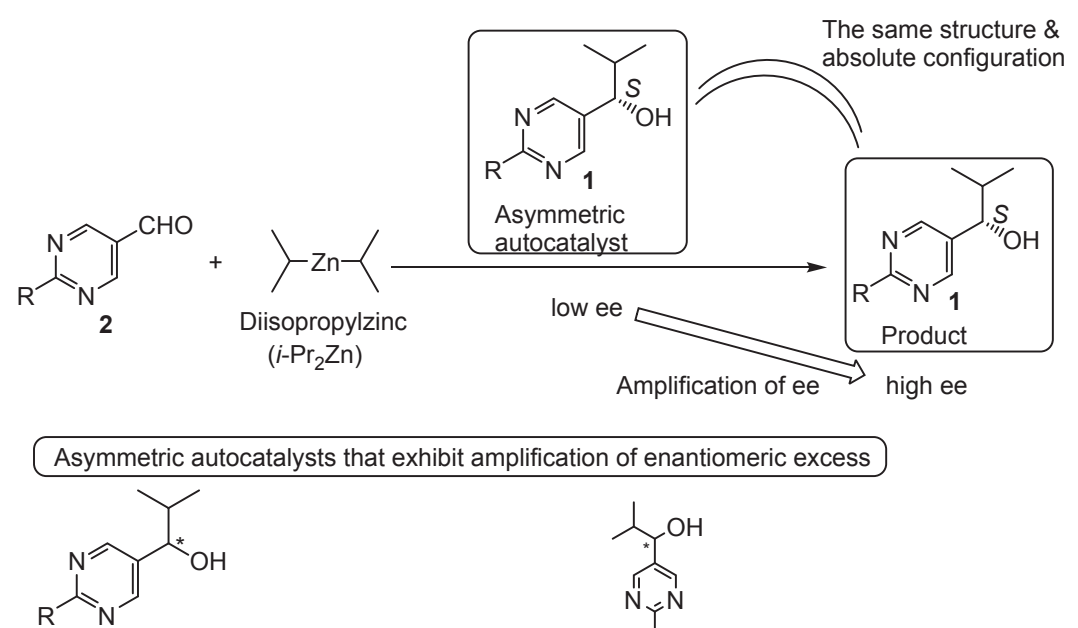

5-pyrimidyl alkanol 1a-f

a: $\mathrm{R}=\mathrm{H}$

b: $\mathrm{CH}_{3}$

c: $\quad \mathrm{H}_{3} \mathrm{C}$ $\mathrm{H}_{3} \mathrm{C}-\mathrm{C}-\mathrm{C} \equiv \mathrm{C}-$ $\mathrm{H}_{3} \mathrm{C}^{\prime}(t-\mathrm{Bu}=)$

d: $\quad\left(\mathrm{H}_{3} \mathrm{C}\right)_{3} \mathrm{Si}-\mathrm{C} \equiv \mathrm{C}-$<smiles>CC=CC(C)(C)C</smiles>

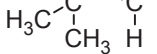

f: $\quad \mathrm{H}_{3} \mathrm{C} \quad \mathrm{CH}_{3}$ $\mathrm{H}_{3} \mathrm{C}-{ }^{-} \mathrm{C}-\mathrm{I}$
$\mathrm{H}_{3} \mathrm{C}^{\prime} \quad \stackrel{\mathrm{I}}{\mathrm{C}^{2}} \mathrm{CH}_{3}$<smiles>CC(C)C(O)c1cnc2ccccc2c1</smiles>

3-quinolyl alkanol 4

Scheme 3. Asymmetric autocatalysis with amplification of enantiomeric excess of 5-pyrimidyl alkanol 1, multifunctionalized pyrimidyl alkanol 3, 3-quinolyl alkanol 4, and 5-carbamoyl-3-pyridyl alkanol $\mathbf{5}$ in reactions with the corresponding aldehydes and diisopropylzinc.

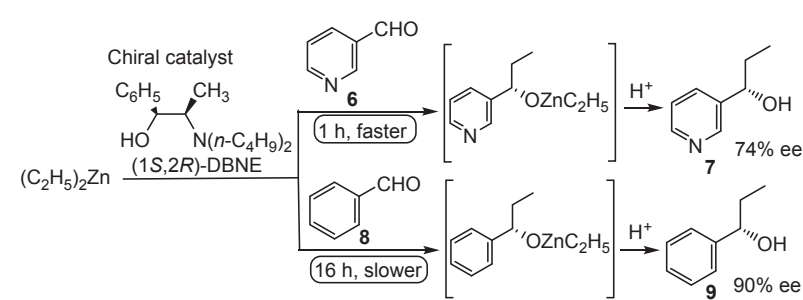

Scheme 4. Enantioselective reactions of pyridine-3-carbaldehyde 6 and benzaldehyde 8 with diethylzinc using $(1 S, 2 R)-N, N$ dibutylnorephedrine (DBNE) as chiral catalyst. pyrimidyl alkanol $\mathbf{1 c}$ to $>99.5 \%$ and the amount of alkanol $\mathbf{1 c}$ by a factor of $c a .630,000$ times. ${ }^{25)}$

It should be noted that this amplification of ee was achieved without the need for any chiral auxiliary other than the initial tiny enantiomeric imbalance of the asymmetric autocatalyst itself, thereby proving the existence of an actual chemical reaction in which very slight enantioenrichment can be amplified significantly to almost enantiopure $(>99.5 \%$ ee) by the mechanism of asymmetric autocatalysis. 


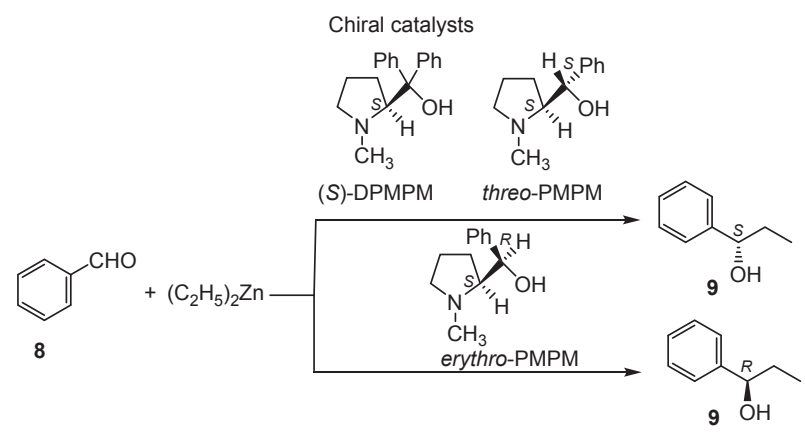

Scheme 5. Enantioselective reaction of benzaldehyde with diethylzinc using $(S)$-DPMPM and its analogs (threo- and erythroPMPM) as chiral catalysts.

2.4. Mechanistic insights into asymmetric autocatalysis of 5-pyrimidyl alkanol. The automultiplication of a chiral compound and the enormous amplification of ee are the most significant

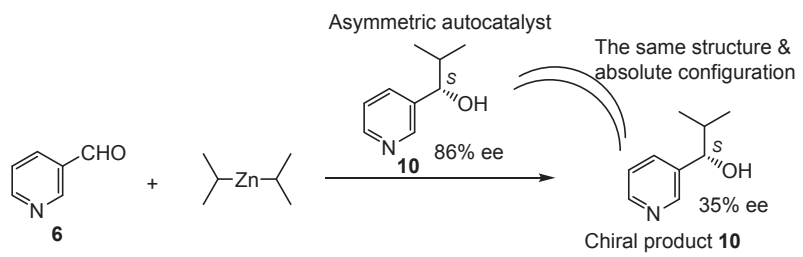

Scheme 6. The first asymmetric autocatalysis of 3-pyridyl alkanol 10.

features of the asymmetric autocatalysis of 5-pyrimidyl alkanol. The enormous amplification of ee in asymmetric autocatalysis is spectacular. Thus, mechanistic insights into the asymmetric autocatalysis have attracted great attention.

We observed the relationship between the reaction time and yield of the product in the asymmetric autocatalytic reaction using an enantiopure pyrimidyl alkanol 1c. ${ }^{49)}$ The result exhibited

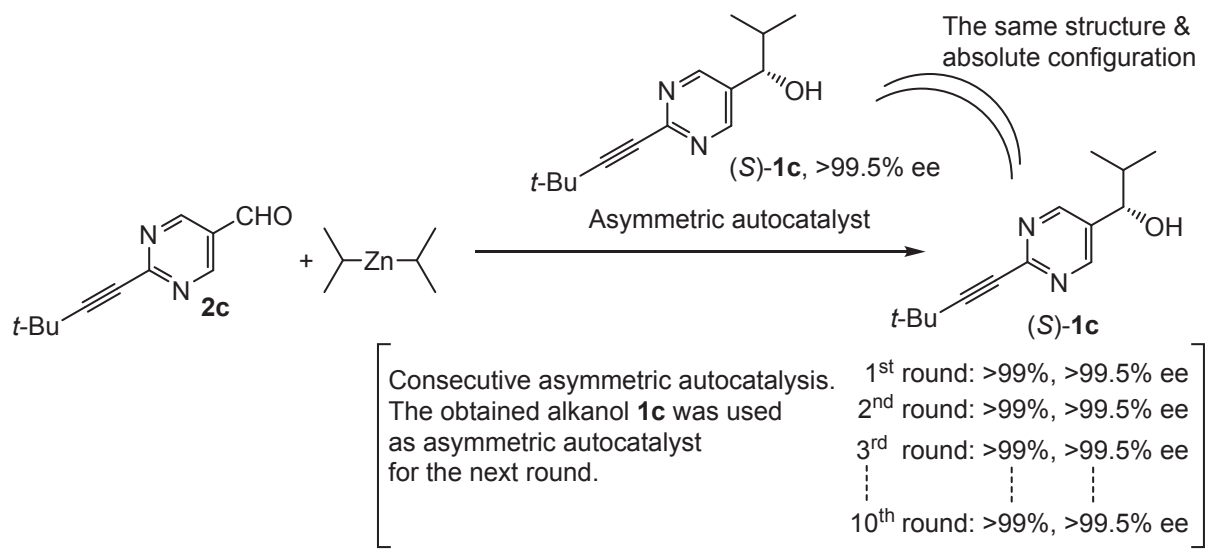

Scheme 7. Practically perfect asymmetric autocatalysis of 2-alkynyl-5-pyrimidyl alkanol 1c.

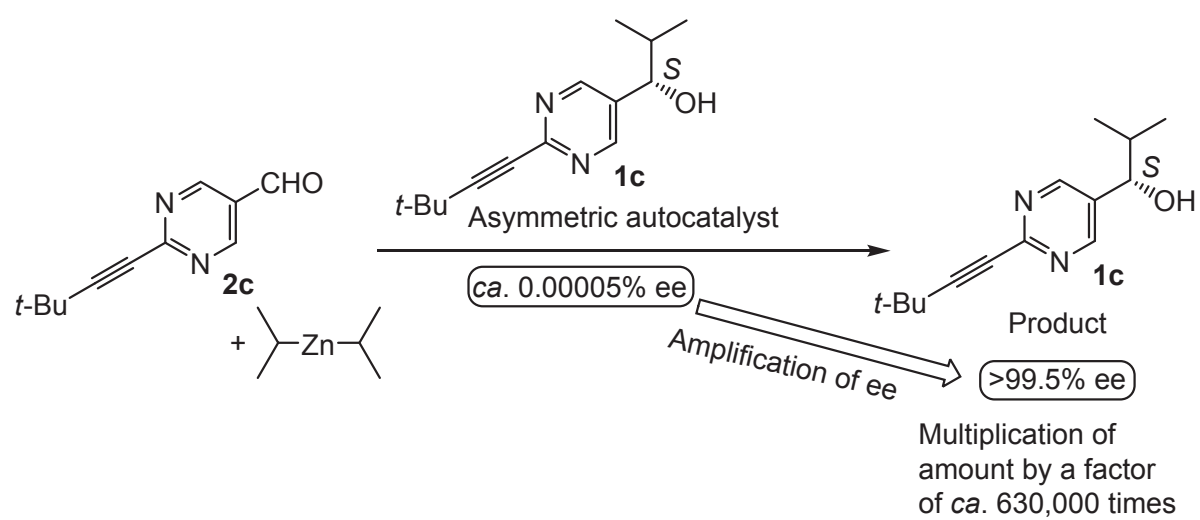

Scheme 8. Significant amplification of enantiomeric excess (ee) from extremely low to greater than $99.5 \%$ ee in asymmetric autocatalysis of 5-pyrimidyl alkanol 1c. 


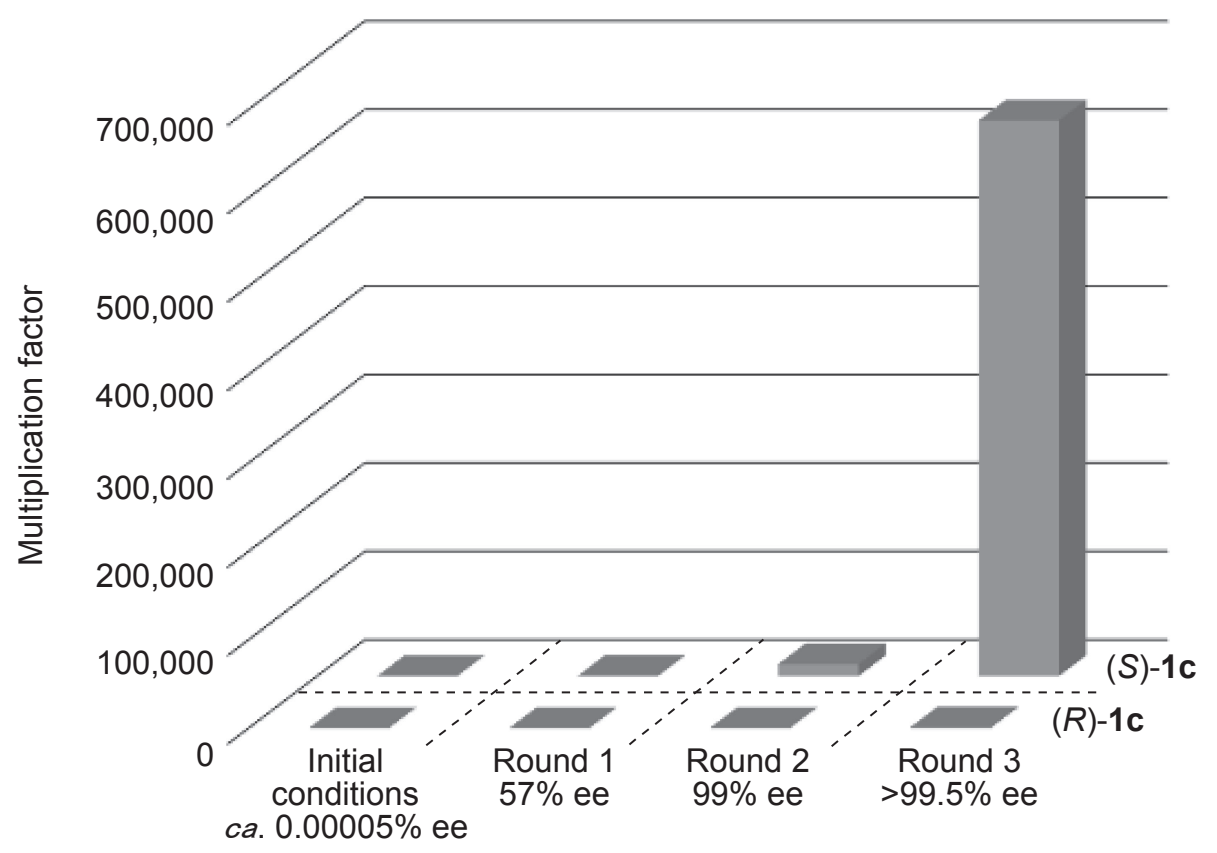

Fig. 2. Asymmetric autocatalysis of 5-pyrimidyl alkanol 1c with amplification of ee.

a sigmoidal curve of product formation. We also reported the kinetic analysis of asymmetric autocatalysis of pyrimidyl alkanol 1c with various ee by using chiral HPLC. ${ }^{50}$ ) These kinetic analyses revealed the dimeric structure of the catalytic species when the ee of the initial asymmetric autocatalyst is moderate or high based on the analogy of nonautocatalytic asymmetric dialkylzinc addition to aldehydes. ${ }^{51)}$ However, when the ee of the initial asymmetric autocatalyst is low, the actual rate of amplification of ee was more significant than that simulated by the dimeric model. Thus, more aggregation of the catalyst than the dimer was envisaged. ${ }^{50)}$

Several groups examined the mechanism and modeling of asymmetric autocatalysis of pyrimidyl alkanol. Early kinetic analysis by measurement with a microcalorimeter proposed the dimeric catalyst model. ${ }^{52)}$ Direct observation of the reaction solution by NMR proposed the presence of dimeric and tetrameric species. ${ }^{53), 54)}$ The DFT calculation study proposed the structure of catalyst aggregates. ${ }^{55)-57)}$ Reaction models of spontaneous symmetry breaking, i.e. absolute asymmetric synthesis, have been proposed. These approaches also proposed the mechanisms of asymmetric autocatalysis of pyrimidyl alkanol. ${ }^{58)-65)}$

We found that the crystal structures of asymmetric autocatalysts 1c are either tetrameric or oligomeric, as determined by X-ray diffraction (Fig. 3). ${ }^{66), 67)}$ The tetramer structure of an asymmetric autocatalyst was determined by single-crystal X-ray diffraction analysis. Two square $\left(\mathrm{Zn}_{2} \mathrm{O}_{2}\right)$ dimers are bridged by one 12-membered macrocycle structure with the coordination of 6 or $4 \mathrm{~mol}$ of $i$ $\mathrm{Pr}_{2} \mathrm{Zn}$ to the nitrogen atoms of pyrimidine rings (Fig. 3c). Both enantiopure (Fig. 3a) and racemic (Fig. 3b) pyrimidyl alkanols form the tetrameric crystal structure. However, these conformations differ from each other. In the enantiopure tetrameric crystal, two square $\left(\mathrm{Zn}_{2} \mathrm{O}_{2}\right)$ dimers are positioned on the same side of the macrocycle (Fig. 3a). In the racemic tetramer, by contrast, square dimers $\left(\mathrm{Zn}_{2} \mathrm{O}_{2}\right)$ are positioned on opposite sides (Fig. 3b). Consequently, the enantiopure tetrameric structure is more sterically crowded than the racemic tetramer. Each $\mathrm{Zn}_{2} \mathrm{O}_{2}$ square has a coordinatively unsaturated zinc atom (Fig. 3c). When a lower amount of $i-\mathrm{Pr}_{2} \mathrm{Zn}$ was used, higher oligomeric species crystallized.

In asymmetric autocatalysis, along with the propagation of the reaction, the concentration of the asymmetric autocatalyst increases and the concentration of $i$ - $\mathrm{Pr}_{2} \mathrm{Zn}$ and aldehyde decreases. Thus, it is probable that the aggregation structures of the asymmetric autocatalyst are not the same between the early and final stages of the reaction. Although the crystal structures do not display the solution structures directly, structural information 
(a)

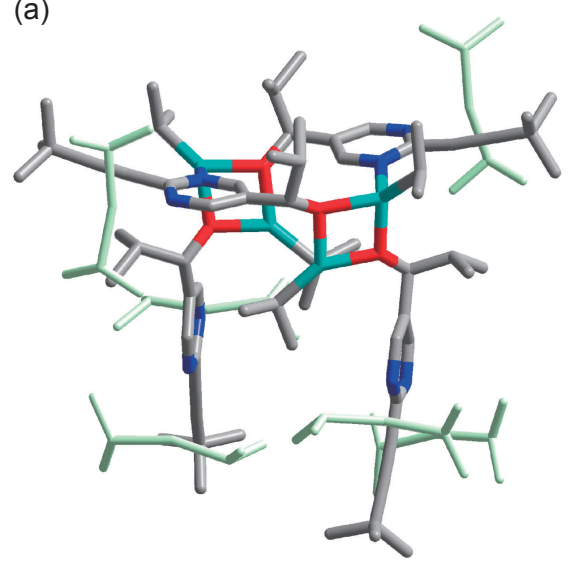

[Zn alkoxide of $(S)-1 \mathrm{c}]_{4} \cdot\left[i-\mathrm{Pr}_{2} \mathrm{Zn}\right]_{6}$ (b)

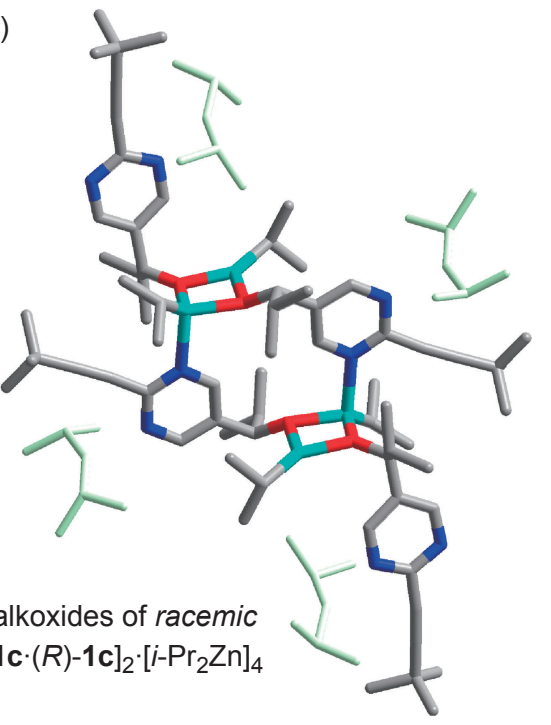

(c)

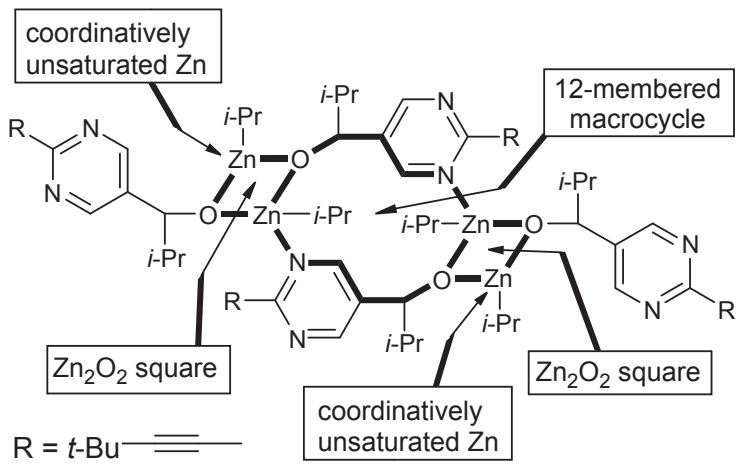

Fig. 3. Crystal structures of (a) enantiopure and (b) racemic tetrameric zinc alkoxides of pyrimidyl alkanol 1c determined by X-ray diffraction analysis.

on the crystals provides useful insight to assist in better understanding the mechanism of asymmetric autocatalysis with amplification of ee.

Furthermore, NMR studies suggest the existence of an acetal transition state involving an acetal moiety. ${ }^{54)}$ DFT calculations were used to investigate a mechanism that involved an acetal. ${ }^{68)}$ Very recent reaction modeling showed that the tetramer or higher order aggregates work effectively for the amplification of chirality. ${ }^{69)}$

Although the entire reaction pathway has not yet been fully clarified, according to studies being carried out by various groups, the mechanism of asymmetric autocatalysis should be clarified in the near future.

\section{Examination of the origins of chirality by using asymmetric autocatalysis with amplification of chirality}

The origin of homochirality has been a long- standing problem and has attracted broad interests from many scientists. ${ }^{2)-10)}$ In most cases, the ee induced by the proposed theories of the origin of chirality has been very low. Moreover, in some of the proposed theories, the induced enantioenrichments are below detection level. The linkage between the induced small enantioenrichment and the enantiopure compounds has thus remained a puzzle. ${ }^{11-20)}$

As described in the preceding section, pyrimidyl alkanol 1 acts as an asymmetric autocatalyst with significant amplification of ee. If a proposed theory of origin of chirality could induce a small enantiomeric imbalance in pyrimidyl alkanol, either directly or indirectly, then the subsequent asymmetric autocatalysis would amplify the ee to almost enantiopure. Using asymmetric autocatalysis with amplification of ee, the theories of the origin of chirality were examined.

3.1. Circularly polarized light. Left $(l)$ - and right $(r)$-circularly polarized light $(\mathrm{CPL})$ has been 


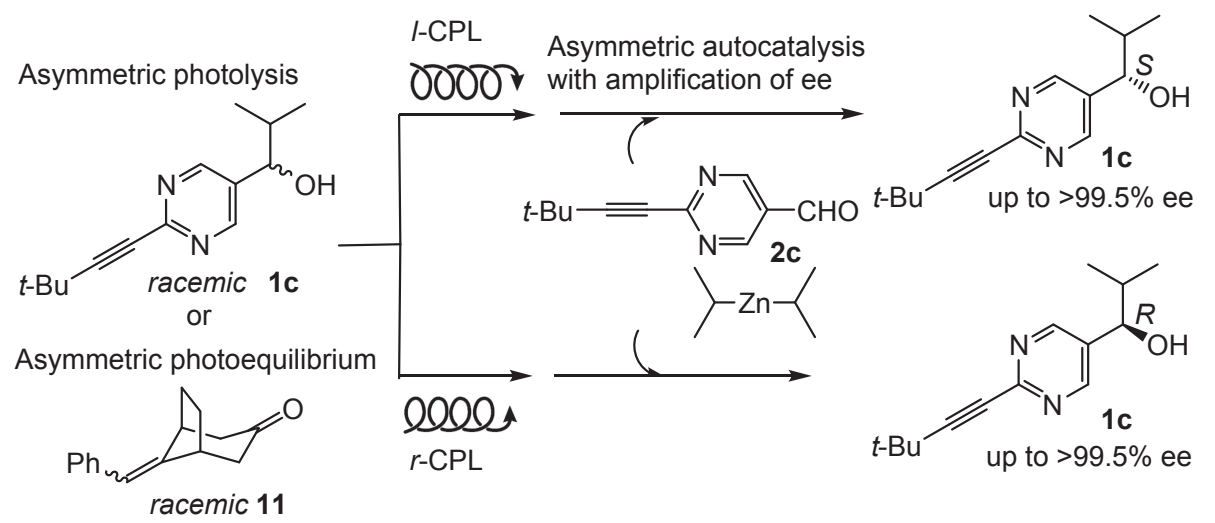

Scheme 9. Asymmetric autocatalysis triggered by direct irradiation of circularly polarized light.

proposed as the origin of chirality of organic compounds such as amino acids. ${ }^{5)}$ The occurrence of strong CPL is observed in star formation regions. ${ }^{70)} \mathrm{It}$ is known that the asymmetric photolysis of racemic leucine and asymmetric photosynthesis of [6]helicene by the irradiation of CPL induce enantioenrichment with only $c a .2 \%$ ee. ${ }^{5)}$ However, this low ee has not been correlated to the high ee of organic compounds. We reported that leucine with low $2 \%$ ee acts as a chiral trigger of asymmetric autocatalysis to afford the pyrimidyl alkanol of higher ee with corresponding absolute configurations. ${ }^{71)}$

Direct irradiation by CPL of the racemic ( $r a c)$ pyrimidyl alkanol 1c, i.e., asymmetric autocatalyst, was examined. Rac-1c was irradiated with $l$-CPL, and the subsequent asymmetric autocatalysis afforded highly enantioenriched $(S)$-alkanol 1c with $>99.5 \%$ ee (Scheme 9). ${ }^{72)}$ In contrast, irradiation with $r$-CPL in conjunction with asymmetric autocatalysis afforded $(R)$-1c with $>99.5 \%$ ee.

The correlation between the chirality of the CPL and $(R)$ - or $(S)$-1c can be rationalized as follows. In their circular dichroism (CD) spectra at $313 \mathrm{~nm},(R)$ 1c and $(S)$-1c exhibit positive and negative Cotton effects, respectively. Therefore, the direct irradiation of $l$-CPL to $r a c$-1c would induce the asymmetric photolysis of $(R)-\mathbf{1 c}$ in preference. Then, the remaining greater amount of $(S)$-1c acts as an asymmetric autocatalyst with amplification of chirality to afford $(S)$-1c with high ee. In this overall process, a direct correlation was achieved for the first time between the chirality of the CPL and that of an organic compound with a very high ee. Asymmetric photoequilibrium of racemic olefin $\mathbf{1 1}$ with the CPL in conjunction with asymmetric autocatalysis also afforded pyrimidyl alkanol 1c with high ee. ${ }^{73)}$
3.2. Chiral inorganic crystals such as quartz and cinnabar as the origin of chirality. Certain natural minerals are known to occur as chiral crystals. Rotation of plane-polarized light, i.e., optical activity, was first found in a quartz sample. Quartz exhibits enantiomorphism and is a chiral mineral; therefore, it has long been discussed as the possible origin of chirality of organic compounds. Quartz has been used to induce enantioenrichment of organic compounds, but no significant asymmetric induction using quartz has been reported.

Asymmetric autocatalysis was examined using $d$ - and $l$-quartz as chiral triggers. ${ }^{74)}$ When pyrimidine-5-carbaldehyde $\mathbf{2 c}$ and $i-\mathrm{Pr}_{2} \mathrm{Zn}$ were reacted in the presence of $d$-quartz powder, $(S)$-pyrimidyl alkanol 1c with $97 \%$ ee was obtained in $95 \%$ yield (Scheme 10). By contrast, in the presence of $l$-quartz, asymmetric autocatalysis was triggered to afford $(R)$ alkanol 1c with $97 \%$ ee in $97 \%$ yield. These results clearly indicate that quartz acts as the origin of chirality, in conjunction with asymmetric autocatalysis, to afford alkanols 1c with high ee and with absolute configurations correlated with those of quartz. A low ee induced in the initially formed zinc alkoxide of pyrimidyl alkanol (induced by chiral quartz) was amplified significantly by subsequent asymmetric autocatalyses to afford 1c with very high ee. Thus, the chirality of an inorganic crystal was correlated, for the first time, to the chirality of an organic compound with very high ee.

Sodium chlorate $\left(\mathrm{NaClO}_{3}\right)$ and sodium bromate $\left(\mathrm{NaBrO}_{3}\right)$ are chiral inorganic ionic crystals. Asymmetric autocatalysis using $d-\mathrm{NaClO}_{3}$ as a chiral trigger afforded $(S)$-alkanol 1c with high ee, while $l-\mathrm{NaClO}_{3}$ afforded $(R)-\mathbf{1 c}{ }^{75)}$ On the other hand, asymmetric autocatalysis in the presence of $d$ - 


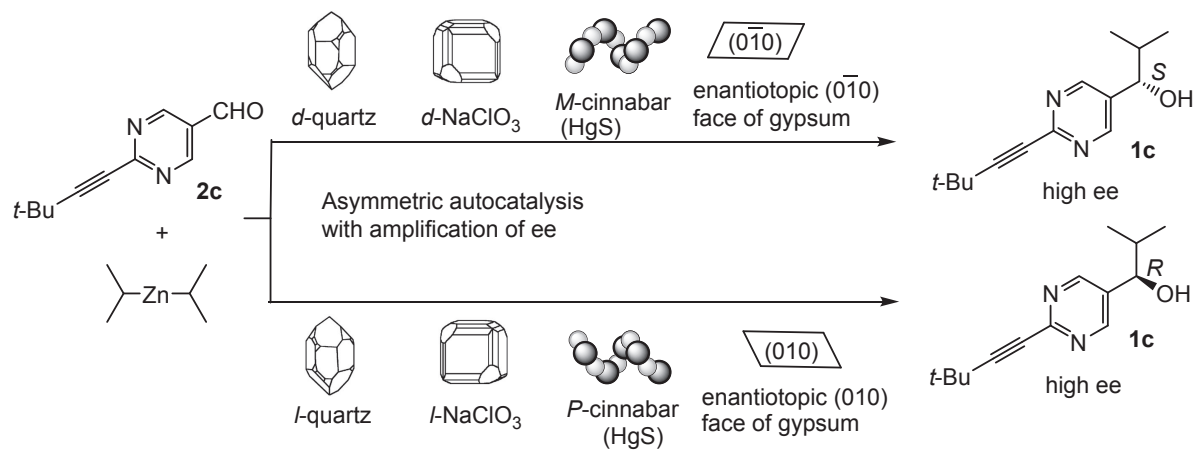

Scheme 10. Asymmetric autocatalysis triggered by chiral inorganic crystals and by enantiotopic face of achiral gypsum.

$\mathrm{NaBrO}_{3}$ afforded $(R)$-1c, while $l-\mathrm{NaBrO}_{3}$ afforded $(S)$-1c. ${ }^{76)}$ These correlations are in agreement with the fact that the signs of optical activity for $\mathrm{NaClO}_{3}$ and $\mathrm{NaBrO}_{3}$ in the same enantiomorph are opposite. Thus, in this asymmetric autocatalysis, the crystals in the same enantiomorph have the same sense of enantioselectivity.

Cinnabar is a red-colored chiral helical crystal of mercury(II) sulfide ( $\alpha$-HgS) that has been used as a pigment for seal stamps and paint, and as a traditional Chinese medicine. Enantiomorphous $P$ - and $M$-crystals of cinnabar are constructed with $-\mathrm{S}-\mathrm{Hg}-$ $\mathrm{S}-\mathrm{Hg}-$ spiral chains. It was found that $P$-HgS triggered asymmetric autocatalysis to afford $(R)-\mathbf{1 c}$ with high ee. ${ }^{77)}$ On the other hand, $M$-HgS afforded $(S)$-1c with high ee. Retgersite (nickel sulfate hexahydrate) is a naturally occurring mineral that exhibits enantiomorphism. It was also found that retgersite acts as a chiral trigger of asymmetric autocatalysis. $^{78)}$

Gypsum (calcium sulfate dihydrate) is a common mineral. It has been used for sculptures, plaster boards in buildings, and plaster casts for medical use. Although the crystal structure of gypsum is achiral, gypsum exhibits the two-dimensional enantiotopic cleavage (010) and (0-10) face that readily appears upon slicing of the crystal. Pyrimidine-5carbaldehyde $\mathbf{2 c}$ was placed on the enantiotopic (010) face of gypsum and exposed to the vapor of $i$-Pr ${ }_{2} \mathrm{Zn}^{79)}(R)$-Alkanol 1c was formed. The ee of $\mathbf{1 c}$ was amplified by the subsequent asymmetric autocatalyses. The reaction on the opposite enantiotopic (0-10) face afforded $(S)$-alkanol 1c. Thus, the enantiotopic surface of an achiral inorganic crystal was found to act as a chiral trigger of asymmetric autocatalysis.

As described, in conjunction with asymmetric autocatalysis, chiral inorganic crystals and the enantiotopic face of an achiral inorganic crystal act as the origins of chirality to afford organic compounds with the correlated absolute configurations with high ee.

3.3. Chiral crystals composed of achiral organic compounds. Certain classes of achiral organic compounds are known to form chiral crystals. The use of these chiral organic crystals as reactants in certain stereospecific reactions has been reported. However, chiral organic crystals consisting of achiral organic compounds have rarely been used as chiral catalysts or initiators in an enantioselective reaction. Investigations were therefore carried out to determine whether chiral crystals composed of achiral organic compounds could act as chiral triggers in asymmetric autocatalysis (Scheme 11).

Cytosine is an achiral compound and an achiral nucleobase that is formed under prebiotic conditions. Crystallization from methanol affords chiral crystals that exhibit either plus or minus Cotton effects in solid-state CD spectra at ca. $310 \mathrm{~nm}$. Chiral crystals of cytosine have been used as chiral triggers for asymmetric autocatalysis. Using the $\left[\mathrm{CD}(+) 310_{\text {Nujol }}\right]-$ cytosine crystal as a chiral trigger, the reaction between aldehyde 2c and $i-\mathrm{Pr}_{2} \mathrm{Zn}$ afforded enantioenriched $(R)$-alkanol 1c with $99.5 \%$ ee in conjunction with asymmetric autocatalysis with amplification of ee. ${ }^{80)}$ On the other hand, in the presence of the $\left[\mathrm{CD}(-) 310_{\text {Nujol }}\right]$-cytosine crystal as a chiral trigger, the reaction afforded enantioenriched $(S)$-1c with $99.5 \%$ ee. These results indicate that the chiral crystal of achiral cytosine acts as the chiral source of the resulting 1c.

With regard to the formation of cytosine chiral crystal, we found an unprecedented type of the origin of chirality. The achiral crystal of cytosine monohydride is known to be formed after the crystallization of cytosine from water. It was found that the 

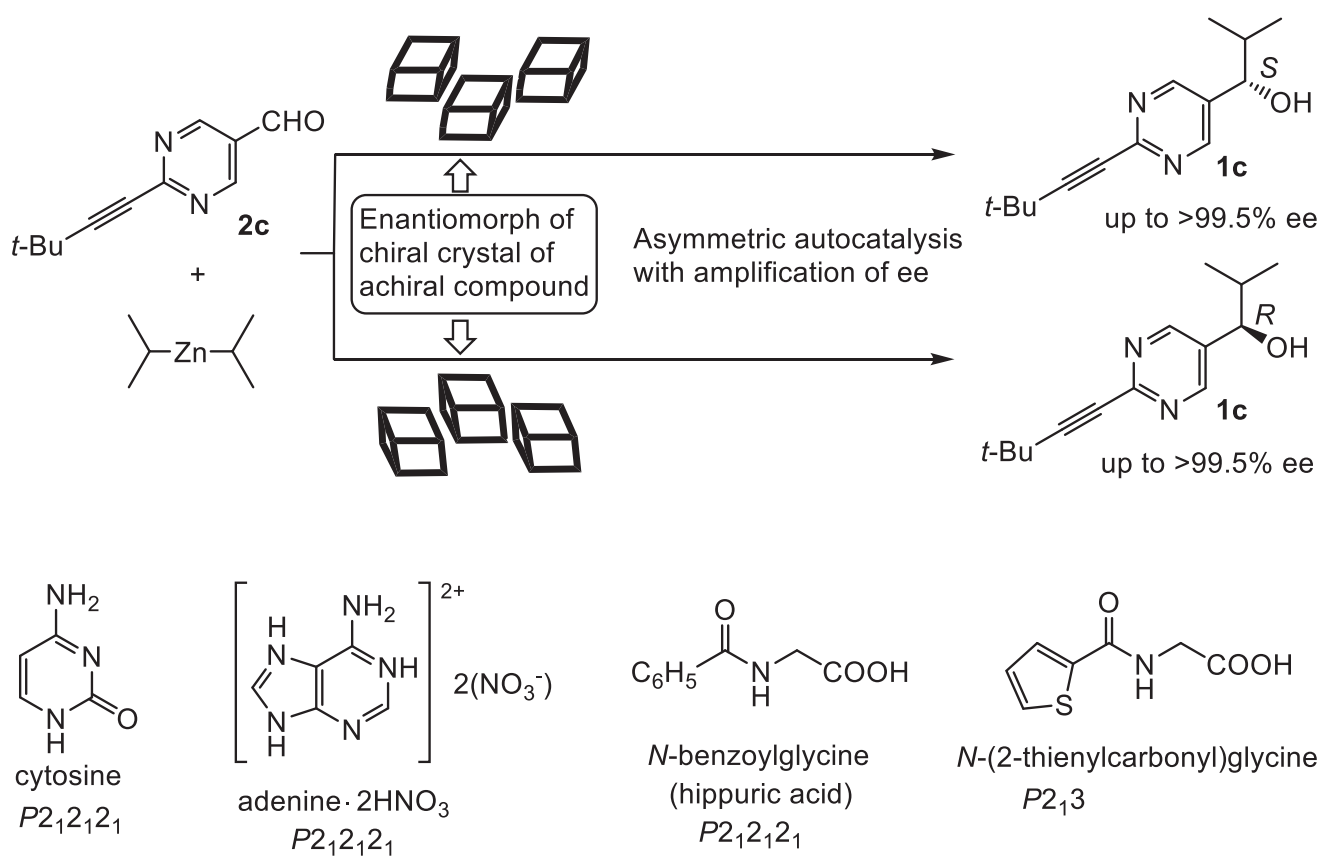
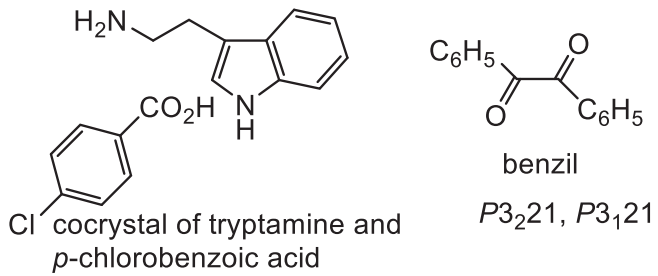

$P 3_{2} 21, P 3_{1} 21$ $P 2{ }_{1} 2_{1} 2_{1}$<smiles>[R]OC(=O)c1cc(C([R])=O)cc(C([R])=O)c1</smiles>

tris(2-hydroxyethyl) 1,3,5benzenecarboxylate $P 6_{1}, P 6_{5}$<smiles>C(=C(c1ccccc1)c1ccccc1)c1ccccc1</smiles>
tetraphenylethylene $P 2_{1}$<smiles>Cc1cc(C(C)(C)C)c(O)c(C(C)(C)C)c1</smiles>

2,6-di-tert-butyl-p-cresol

(BHT) $\quad P 2{ }_{1} 2{ }_{1} 2_{1}$
D-serine $\cdot$ L-serine $\cdot \mathrm{H}_{2} \mathrm{SO}_{4} \cdot \mathrm{H}_{2} \mathrm{O}$

(DL-diserinium sulfate hydrate) $P 2{ }_{1}{ }_{1} 2_{1}$
$\left(\mathrm{CH}_{2} \mathrm{NH}_{2}\right)_{2} \cdot \mathrm{H}_{2} \mathrm{SO}_{4}$

ethylenediamine sulfate

$P 4{ }_{1} 2{ }_{1} 2, P 4{ }_{3} 2{ }_{1} 2$

Scheme 11. Asymmetric autocatalysis triggered by chiral crystals of achiral or racemic organic compounds.

elimination of the crystal water by heating one of the enantiotopic faces of an achiral crystal of cytosine monohydrate affords a chiral crystal of dehydrated cytosine. $^{81)}$ The chirality of the formed dehydrated cytosine crystal is correlated with the enantiotopic face of the achiral cytosine monohydrate crystal. It was also found that dehydration of crystal water under reduced pressure, instead of heating, from the same enantiotopic face affords a chiral dehydrate cytosine crystal with the opposite chirality. ${ }^{82)}$ These results offer the first example of the formation of chiral crystals with controlled chirality by the dehydration of crystal water from an achiral crystal.

Adenine is an achiral nucleobase. Adenine dinitrate forms chiral crystals. Chiral crystals composed of adenine dinitrate act as chiral triggers for asymmetric autocatalysis of pyrimidyl alkanol $\mathbf{1} \mathbf{c}^{83)}$ which indicates that achiral nucleobases such as cytosine and adenine in their chiral crystalline state act as the origins of chirality. 


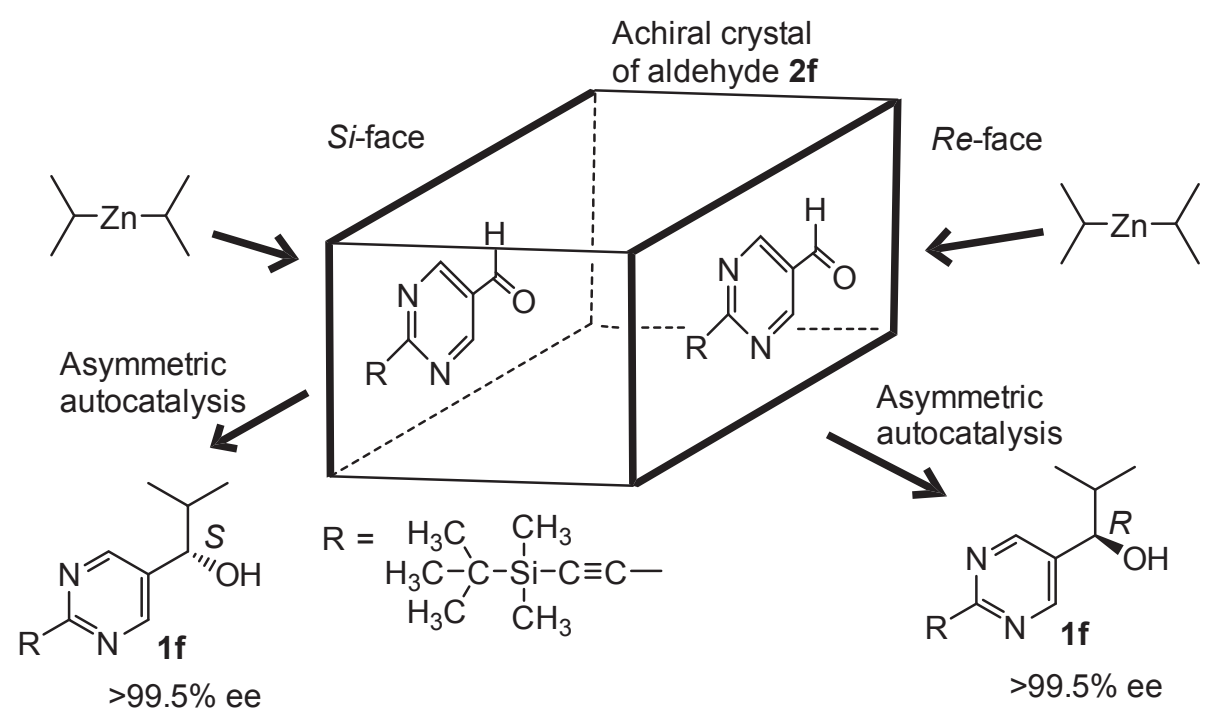

Scheme 12. Enantioselective addition of diisopropylzinc at the enantiotopic surface of achiral single crystal of 2-(tert-butyldimethylsilylethynyl)pyrimidine-5-carbaldehyde $\mathbf{2}$ f followed by asymmetric autocatalysis.

It was also found that enantiomorphous crystals composed of achiral $N$-benzoylglycine, $\left.{ }^{84}\right) \mathrm{N}$-(2-thienylcarbonyl)glycine, ${ }^{85)}$ cocrystal of tryptamine and $p$-chlorobenzoic acid, ${ }^{86)}$ benzil ${ }^{87)}$ tetraphenylethylene, ${ }^{88)}$ ethylenediamine sulfate, ${ }^{89)}$ benzene triester ${ }^{90)}$ and 2,6-di-t-butyl- $p$-cresol $(\mathrm{BHT})^{91)}$ act as chiral triggers for asymmetric autocatalysis of 1c. Thus, asymmetric autocatalysis could serve as a macroscopic observation tool of molecular-level information on the structure of crystal surfaces. ${ }^{85)}$

A chiral crystal composed of a racemic organic compound can also act as a chiral trigger in asymmetric autocatalysis. The racemate of serine formed the chiral crystal $\left(P 2_{1} 2_{1} 2_{1}\right)$ of DL-diserinium sulfate hydrate. $M$-Crystals of DL-diserinium sulfate hydrate triggered asymmetric autocatalysis to afford $(R)$-pyrimidyl alkanol 1c ${ }^{92)}$ By contrast, asymmetric autocatalysis triggered by $P$-crystals afforded $(S)$ alkanol 1c. As described, it was found that chiral crystals formed from a racemic compound acted as a chiral source.

3.4. Asymmetric autocatalysis initiated on the enantiotopic faces of achiral organic crystals of achiral organic compound. There are certain classes of achiral organic compounds that form achiral crystals with enantiotopic faces. 2-(tertButyldimethylsilylethynyl)pyrimidine-5-carbaldehyde $2 \mathbf{f}$ formed an achiral crystal $(P-1)$ with enantiotopic faces (Scheme 12). When one of these faces was exposed to the vapor of $i-\mathrm{Pr}_{2} \mathrm{Zn}$, the exposed $R e$-face of aldehyde was attacked by $i-\mathrm{Pr}_{2} \mathrm{Zn}$ to afford $(R)$ - pyrimidyl alkanol 1f. ${ }^{93)}$ By contrast, exposure of the opposite enantiotopic face (the $S i$-face of aldehyde) afforded $(S)$-alkanol 1f. The ee of the obtained alkanol was amplified to $>99.5 \%$ by the subsequent asymmetric autocatalyses.

3.5. Absolute asymmetric synthesis in conjunction with asymmetric autocatalysis. In his commentary on absolute asymmetric synthesis, Mislow termed absolute asymmetric synthesis as the formation of an enantioenriched compound from achiral compounds without the intervention of any chiral factor. ${ }^{3)}$ Absolute asymmetric synthesis has been proposed as one of the origins of homochirality in nature. However, it is widely accepted that without the intervention of any chiral factor, a racemic chiral product is always formed from achiral compounds (Scheme 13b). This phenomenon is explained as follows: the probability of the formation of $R$ and $S$ products is equal; furthermore, the molecules are produced in huge numbers, and the ratio of $R$ and $S$ enantiomeric products in a reaction is 50:50 (a racemate).

However, according to the theory of statistics, the numbers of the $R$ and $S$ product enantiomers are rarely exactly the same, i.e., there are almost always statistical fluctuations in the numbers of produced enantiomers. ${ }^{94), 95)}$ For example, when a coin is flipped 100 times, the probability of exactly 50 heads and 50 tails is only $8 \%$. In the other $92 \%$ of cases, either heads or tails will be in excess, such as 48 to 52,51 to 49 , and so on. 
(a) Absolute asymmetric synthesis in conjunction with asymmetric autocatalysis
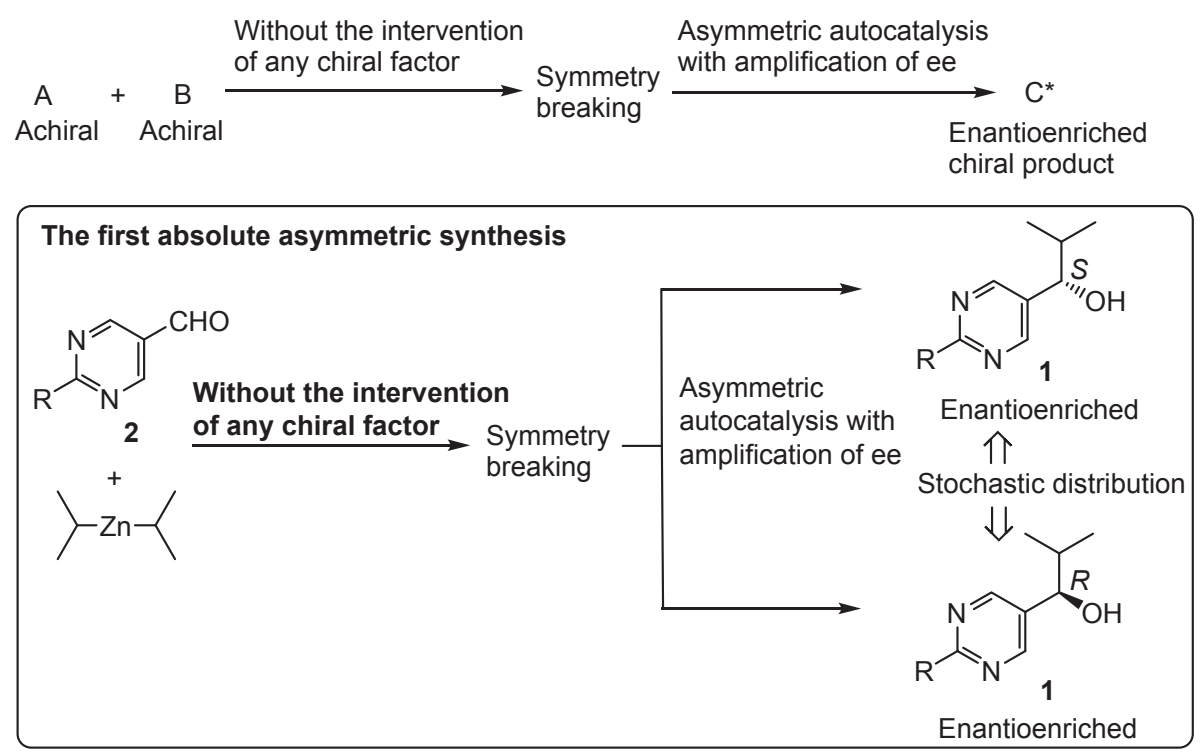

(b) Usual organic reactions without the intervention of any chiral factor give racemic products.

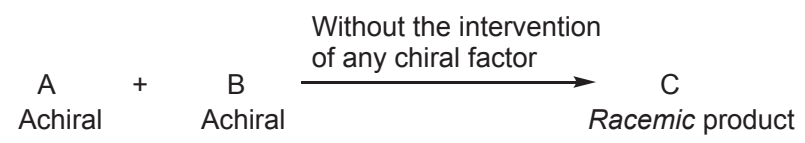

Scheme 13. Absolute asymmetric synthesis in conjunction with asymmetric autocatalysis with amplification of ee.

As described in the preceding section, asymmetric autocatalysis of pyrimidyl alkanol in the reaction between pyrimidine-5-carbaldehyde and $i-\mathrm{Pr}_{2} \mathrm{Zn}$ amplifies very low ee to $>99.5 \%$ ee. ${ }^{25)}$ What would happen if pyrimidine-5-carbaldehyde was reacted with $i-\mathrm{Pr}_{2} \mathrm{Zn}$ without using any chiral factor? The initial small enantioenrichment of the product, i.e., isopropylzinc alkoxide of pyrimidyl alkanol, as a result of the fluctuation in racemic mixtures, could be amplified by the subsequent asymmetric autocatalyses with amplification of ee, and could produce an enantiomerically enriched product (Scheme 13a). Thus, absolute asymmetric synthesis without the intervention of any chiral factor was examined in the reaction between pyrimidine-5-carbaldehyde and $i-\operatorname{Pr}_{2} \mathrm{Zn}^{96), 97)}$

The reactions of pyrimidine-5-carbaldehyde 2c and $i-\mathrm{Pr}_{2} \mathrm{Zn}$ without the intervention of any chiral factor was found to afford enantioenriched $(S)$ - or $(R)$-alkanol 1c with stochastic distributions of formation (Scheme 13a). When aldehyde 2c was reacted with $i-\mathrm{Pr}_{2} \mathrm{Zn}$, the subsequent asymmetric autocatalysis with amplification of ee afforded pyrimidyl alkanol 1c with an ee well above the detection level. The absolute configurations of 1c produced under these conditions exhibited a stochastic distribution of $S$ and $R$ enantiomers: $(S)-\mathbf{1 c}$ formed 19 times and $(R)-\mathbf{1 c}$ formed 18 times (Fig. 4) ${ }^{96)}$ In addition, the reactions between pyrimidine-5-carbaldehyde and $i-\mathrm{Pr}_{2} \mathrm{Zn}$ in the presence of achiral amorphous silica gel ${ }^{98}$ ) and achiral amines ${ }^{99)}$ without using any chiral factor afforded $(S)$-1c or $(R)$-1c in a stochastic manner. Absolute asymmetric synthesis with stochastic distribution of the product was also reported by another group using pyrimidine-5-carbaldehyde $\mathbf{2} \mathbf{b}$ and $i-\mathrm{Pr}_{2} \mathrm{Zn} .{ }^{100)}$

These results of stochastic behavior in the formation of enantioenriched pyrimidyl alkanol constitute one of the conditions necessary for spontaneous absolute asymmetric synthesis. It should be noted that the present absolute asymmetric synthesis is counterintuitive, considering the common knowledge that the reaction between achiral reactants without the intervention of any chiral factor always affords racemic chiral products. Thus, the present results stand as the first example of spontaneous absolute asymmetric synthesis as defined by Mislow. ${ }^{3)}$ 


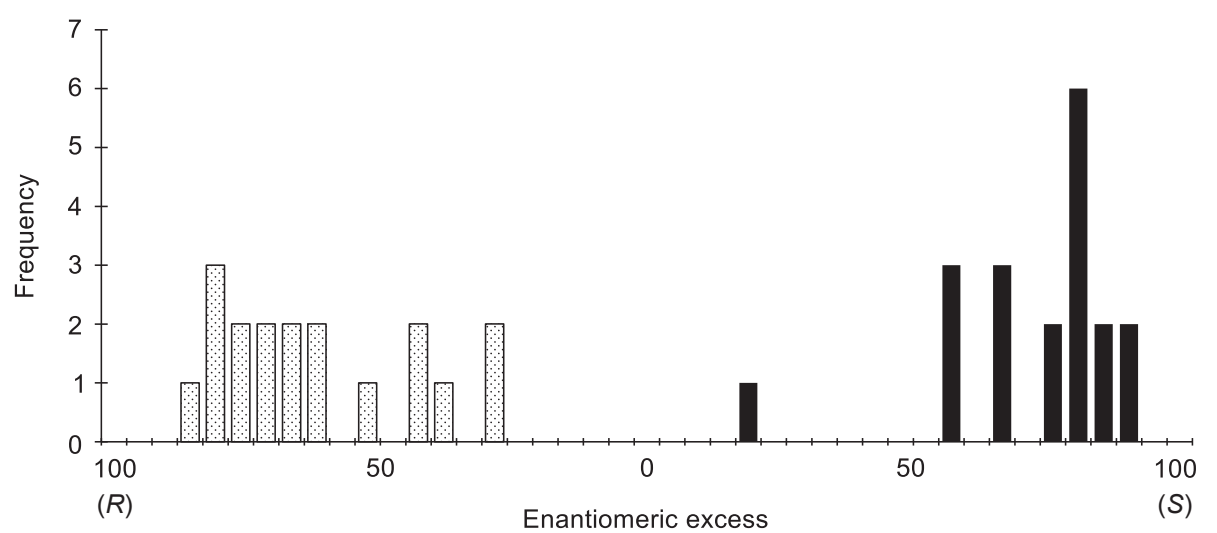

Fig. 4. Histograms of the absolute configurations and ee of the product pyrimidyl alkanol $\mathbf{1} \mathbf{c}$ by absolute asymmetric synthesis in the reaction between pyrimidine-5-carbaldehyde $\mathbf{2} \mathbf{c}$ and diisopropylzinc.

3.6. Asymmetric autocatalysis triggered by chiral compounds arising from hydrogen $(\mathrm{D} / \mathrm{H})$, carbon $\left({ }^{13} \mathrm{C} /{ }^{12} \mathrm{C}\right)$, nitrogen $\left({ }^{15} \mathrm{~N} /{ }^{14} \mathrm{~N}\right)$, and oxygen $\left({ }^{18} \mathrm{O} /{ }^{16} \mathrm{O}\right)$ isotopomers. Asymmetric autocatalysis was applied to the discrimination of chirality of isotopomers. When pyrimidine-5-carbaldehyde 2c is treated with $i$ - $\mathrm{Pr}_{2} \mathrm{Zn}$ using chiral isotopomers as chiral triggers, the sense of absolute configuration of the product 1c should be controlled by the chirality of the external chiral trigger (Scheme 14).

Glycine does not possess any asymmetric carbon atom. However, the compound becomes chiral when one of the hydrogen atoms of the methylene group of glycine is substituted by deuterium. Chiral isotopomers of glycine- $\alpha-d \mathbf{1 2}$ were used as chiral triggers in an asymmetric autocatalysis in the reaction between $i$ $\mathrm{Pr}_{2} \mathrm{Zn}$ and pyrimidine-5-carbaldehyde 2c to afford alkanol 1c with high ee. ${ }^{101)}$ The absolute configuration of the produced alkanol 1c was controlled by the chirality of the trigger resulting from hydrogen isotope substitution. When $i-\mathrm{Pr}_{2} \mathrm{Zn}$ was reacted with aldehyde 2c using a chiral trigger of $(S)$-glycine- $\alpha$ - $d$ 12, $(S)$-pyrimidyl alkanol 1c with high ee was formed. By contrast, in the presence of $(R)$-glycine$\alpha$-d 12, the opposite $(R)-\mathbf{1 c}$ was formed. Chiral deuterated primary alcohols ${ }^{102)}$ can also trigger asymmetric autocatalysis. These results are the first examples of highly enantioselective synthesis induced by chiral compounds owing to deuterium substitution. ${ }^{103)}$

Carbon $\left({ }^{13} \mathrm{C} /{ }^{12} \mathrm{C}\right)$, nitrogen $\left({ }^{15} \mathrm{~N} /{ }^{14} \mathrm{~N}\right)$ and oxygen $\left({ }^{18} \mathrm{O} /{ }^{16} \mathrm{O}\right)$ isotopomers should be much more difficult to discriminate experimentally than $\mathrm{H} / \mathrm{D}$ isotopomers because the chirality originates from the much smaller difference in atomic weight between carbon-13/carbon-12, nitrogen-15/nitrogen-14, and oxygen-18/oxygen-16 (Scheme 14). The induction of detectable enantioenrichment in asymmetric reactions by carbon, nitrogen, and oxygen isotopomers has not been reported earlier. Asymmetric autocatalysis was therefore examined using these carbon, nitrogen, and oxygen isotopomers as chiral triggers.

Many apparently achiral organic molecules on Earth may be chiral because of random substitution of the $1.11 \%$ naturally abundant ${ }^{13} \mathrm{C}$ for ${ }^{12} \mathrm{C}$ in an enantiotopic moiety within a structure. Dimethylphenylmethanol $\mathbf{1 3}$ is an achiral compound because it has two methyl groups on the same carbon atom. However, one of the carbon atoms of the two methyl groups is labeled with ${ }^{13} \mathrm{C}$; hence, the compound becomes a chiral carbon isotopomer. Asymmetric autocatalysis was conducted using the chiral carbon isotopomer of alkanol $\mathbf{1 3}$ as a chiral trigger. ${ }^{104)}$ When $i$ - $\mathrm{Pr}_{2} \mathrm{Zn}$ and aldehyde $\mathbf{2 c}$ were reacted in the presence of $(R)$-dimethylphenylmethanol 13 , arising from ${ }^{13} \mathrm{C}$ substitution of one of the methyl groups, $(R)$-pyrimidyl alkanol 1c with high ee was formed (Scheme 14). By contrast, $(S)$-13 triggered the formation of $(S)$-1c. meso- $N^{2}, N^{2}, N^{3}, N^{3}$-Tetramethyl-2,3-butanediamine $\mathbf{1 4}$ is an achiral compound because, despite the presence of asymmetric carbon atoms, compound 14 is superimposable with its mirror image. However, when one of the nitrogen $\left({ }^{14} \mathrm{~N}\right)$ atoms is substituted by ${ }^{15} \mathrm{~N}$, the diamine $\mathbf{1 4}$ becomes a chiral nitrogen $\left({ }^{15} \mathrm{~N} /{ }^{14} \mathrm{~N}\right)$ isotopomer $\mathbf{1 4}$. When asymmetric autocatalysis was triggered by $\left[{ }^{15} \mathrm{~N}\right](R)$-diamine $14,(R)$ pyrimidyl alkanol 1c was formed with $>99.5 \%$ ee. By contrast, the chiral trigger $\left[{ }^{15} \mathrm{~N}\right](S)$-diamine 14 afforded $(S)$-alkanol 1c with $>99.5 \%$ ee. ${ }^{105)}$ It was also found that oxygen $\left({ }^{18} \mathrm{O} /{ }^{16} \mathrm{O}\right)$ isotopomers of 1,2 diphenyl-1,2-ethanediol $\mathbf{1 5}$ and glycerin acted as chiral triggers of asymmetric autocatalysis. ${ }^{106), 107)}$ 


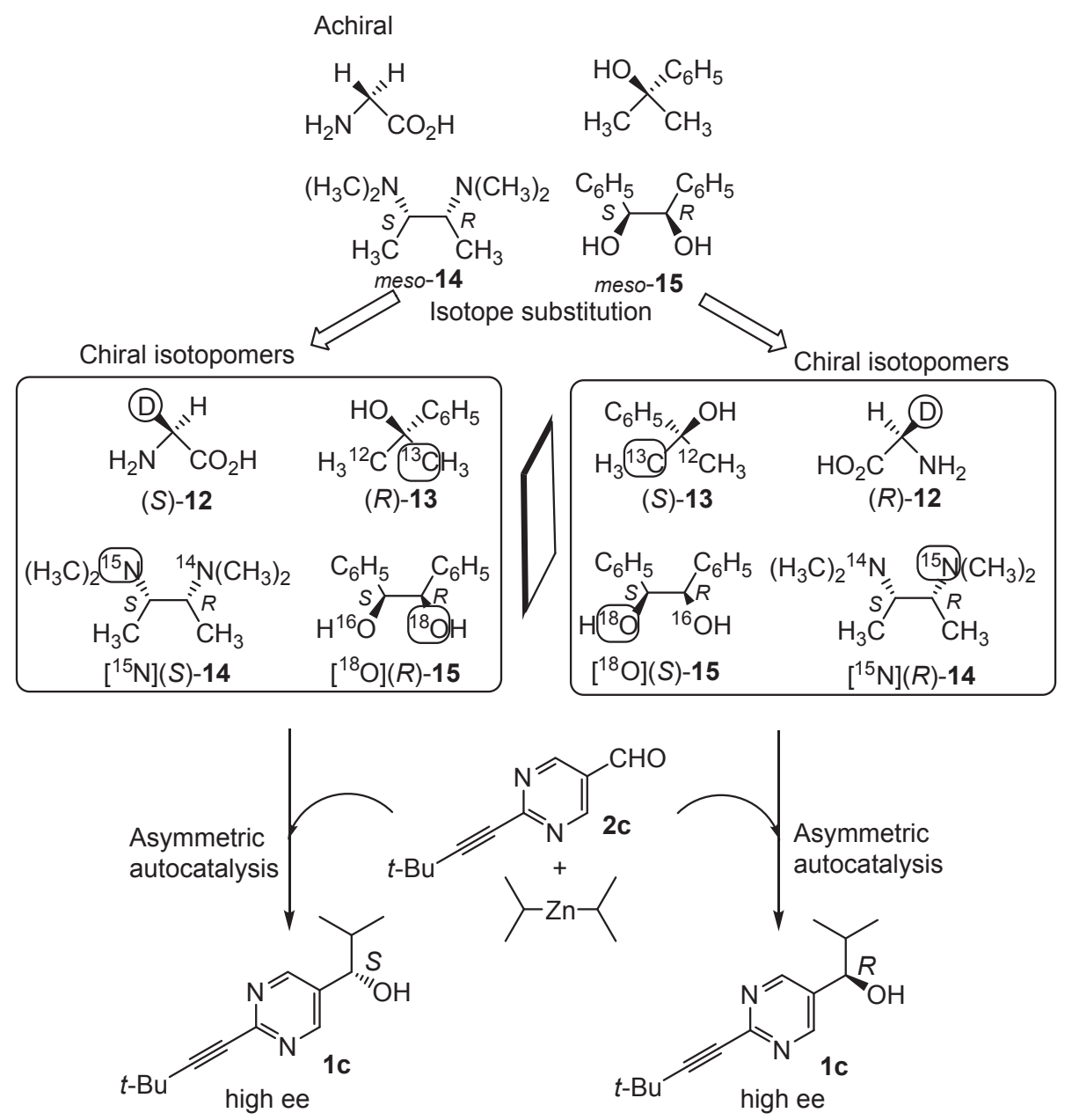

Scheme 14. Asymmetric autocatalysis triggered by chiral compounds arising from hydrogen, carbon, nitrogen, and oxygen isotope substitution.

These asymmetric inductions by carbon, nitrogen, and oxygen isotopically chiral compounds are the first examples in the research field of chirality. The neglected carbon, nitrogen, and oxygen isotope chirality of many organic compounds on Earth can therefore be discriminated by asymmetric autocatalysis with amplification of the extremely small chiral influence between ${ }^{13} \mathrm{C} /{ }^{12} \mathrm{C},{ }^{15} \mathrm{~N} /{ }^{14} \mathrm{~N}$ and ${ }^{18} \mathrm{O} /$ ${ }^{16} \mathrm{O} .{ }^{108), 109)}$

\section{Discrimination of chirality and asymmetric induction by using asymmetric autocatalysis}

Asymmetric autocatalysis with amplification of chirality can be utilized for the chiral discrimination of organic and inorganic compounds and materials. Amino acids, even with low ee, trigger asymmetric autocatalysis to afford pyrimidyl alkanol with the corresponding absolute configuration to that of the chiral trigger. ${ }^{71)}$ Detection of chirality of amino acids and other possible compounds in meteorites, asteroids and planets has been an intriguing subject of astrobiology and the origin of life. Asymmetric autocatalysis may provide a powerful method for further research in this subject.

The chirality of various amino acids $\mathbf{1 6}$ even with low ee can act as chiral triggers of asymmetric autocatalysis of pyrimidyl alkanol 1c (Scheme 15). ${ }^{110)}$ Therefore, based on the absolute configuration of the product alkanol 1c, the absolute configuration of the amino acids can be discriminated. The present asymmetric autocatalysis with amplification of ee may be used to detect the chirality of amino acids as well as any chiral compound in meteorites. ${ }^{111)}$

5-Ethyl-5-propylundecane 17, i.e., ( $n$-butyl)ethyl $(n$-hexyl) $(n$-propyl)methane, is a chiral saturated quaternary hydrocarbon possessing four different 


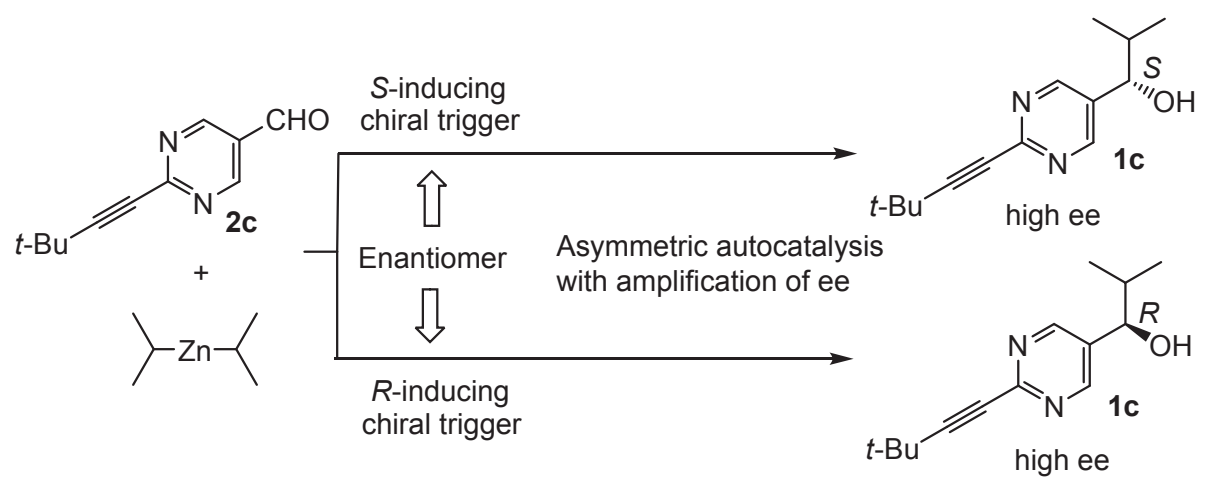<smiles>[R]C(N)C(=O)O</smiles>

amino acids 16 even with low ee<smiles></smiles>

tetrathia[7]helicene 20

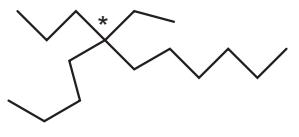

5-ethyl-5-propylundecane 17

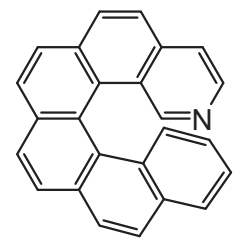

2-aza[6]helicene 21

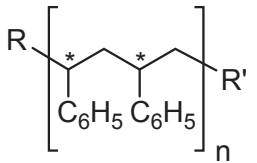

isotactic polystyrene 18

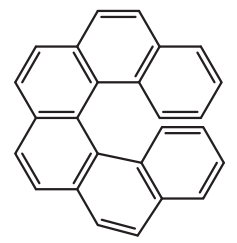

[6]helicene 19

Scheme 15. Discrimination of chirality by asymmetric autocatalysis.

substituents on the asymmetric carbon atom. Because the differences in the structures of the four substituents are so small (compared with each other), the value of the optical rotation of the compound is below detection level. Thus, the spectroscopic method was not useful to discriminate the chirality of the compound. $(R)$ - and $(S)$-Alkane $\mathbf{1 7}$ was found to act as a chiral trigger of asymmetric autocatalysis to afford $(S)$-pyrimidyl alkanol 1c and $(R)$-1c with high ee, respectively (Scheme 15). ${ }^{112)}$ It was also found that cryptochiral isotactic polystyrene $\mathbf{1 8}$ acts as a chiral trigger of asymmetric autocatalysis. ${ }^{113)}$

Helical chirality of $[6]$ helicene $\mathbf{1 9},{ }^{114}$ ) tetrathia[7]helicene $\mathbf{2 0}^{115)}$ and 2-aza[6] helicene $\mathbf{2 1}^{116}$ ) are discriminated by asymmetric autocatalysis. In addition, chirality of artificially designed chiral inorganic helical silica $\mathbf{2 2}$ and mesoporous helical silica $\mathbf{2 3}$ can be discriminated by asymmetric autocatalysis. ${ }^{117), 118)}$

Furthermore, an unusual reversal of the sense of enantioselectivity in asymmetric autocatalysis was observed (Scheme 16). ${ }^{119)}$ Chiral $(1 R, 2 S)-N, N$-dimethylnorephedrine (DMNE) alone triggers the reaction between aldehyde $\mathbf{2 c}$ and $i-\mathrm{Pr}_{2} \mathrm{Zn}$ to afford $(R)$-pyrimidyl alkanol 1c with high ee. When the reaction was triggered by a mixture of $(1 R, 2 S)$ DMNE and achiral $N, N$-dibutylaminoethanol (DBAE), the opposite enantiomer of $(S)$-alkanol 1c was formed. This reversal of the sense of enantioselectivity suggests the formation of aggregation of chiral DMNE and achiral DBAE that results in the opposite enantioselectivity. ${ }^{120)}$ Reversal of the sense of enantioselectivity was also observed by changing the temperature in asymmetric autocatalysis using chiral aromatic alcohols and amines. ${ }^{121)}$ Finally, asymmetric autocatalysis of pyrimidyl alkanol $\mathbf{1}$ was successfully employed in asymmetric synthesis of sec-alkanols ${ }^{122)}$ and chiral amplification of alkynyl alkanols. $^{123)}$

\section{Conclusions}

Asymmetric autocatalysis with amplification of enantiomeric excess (ee) was found in the reaction between pyrimidine-5-carbaldehyde and $i$ - $\mathrm{Pr}_{2} \mathrm{Zn}$ (Soai reaction). The ee of $(S)$-2-alkynylpyrimidyl 


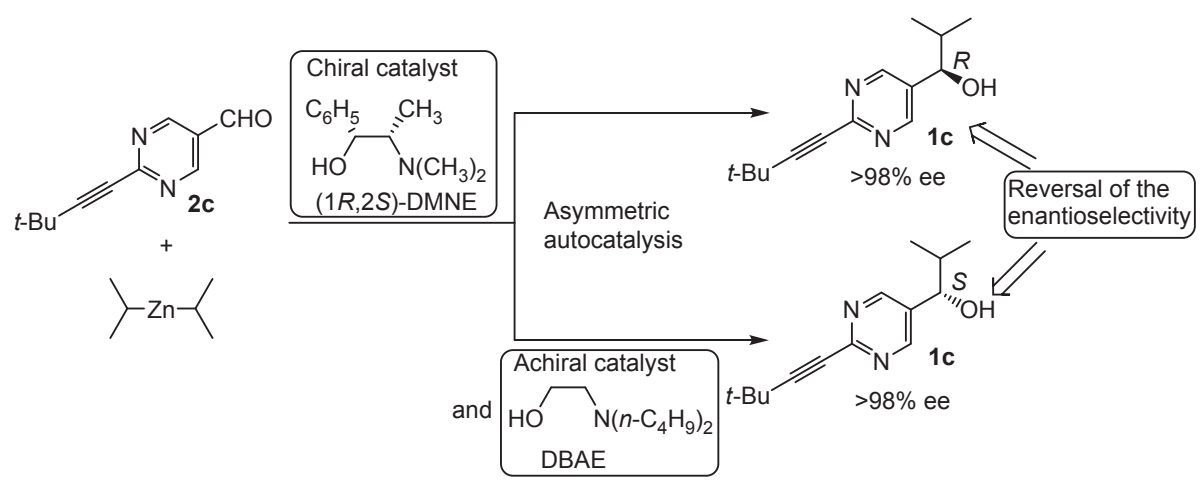

Scheme 16. Unusual reversal of the sense of enantioselectivity by the addition of achiral catalyst in asymmetric autocatalysis.

alkanol 1 with as low as ca. $0.00005 \%$ ee was amplified to $>99.5 \%$ ee during three consecutive asymmetric autocatalytic reactions, together with multiplication of its amount by ca. 630,000 times. This asymmetric autocatalysis stands as the first example of catalytic self-replication, i.e., automultiplication, of chiral compounds. Amplification of ee by asymmetric autocatalysis is unique in that no chiral factor other than the enantiomeric imbalance of asymmetric autocatalyst itself is required. The asymmetric autocatalysis is also the first example of the catalytic automultiplication of a chiral compound.

Asymmetric autocatalysis has been applied to the study of the origin of homochirality. The low ees induced by the origin of chirality can be amplified to very high ees observed in nature. Using asymmetric autocatalysis, the chirality of CPL is directly correlated with the chirality of the pyrimidyl alkanol with high ee. Chiral inorganic crystals such as quartz and cinnabar can act as chiral triggers. Chiral organic crystals formed from achiral compounds can also act as chiral triggers of asymmetric autocatalysis. The enantiotopic faces of an achiral organic crystal are also chiral triggers of asymmetric autocatalysis. Chiral symmetry breaking by spontaneous absolute asymmetric synthesis, i.e., the formation of enantioenriched $(S)$ - and $(R)$-compounds with bimodal distribution, without the intervention of a chiral auxiliary was realized in conjunction with asymmetric autocatalysis. Asymmetric autocatalysis is triggered by amino acids that are chiral because of hydrogen isotope substitution.

Chiral carbon $\left({ }^{13} \mathrm{C} /{ }^{12} \mathrm{C}\right)$, nitrogen $\left({ }^{15} \mathrm{~N} /{ }^{14} \mathrm{~N}\right)$, and oxygen $\left({ }^{18} \mathrm{O} /{ }^{16} \mathrm{O}\right)$ isotopomers can trigger asymmetric autocatalysis. These results offer the first examples of asymmetric reactions induced by carbon, nitrogen, and oxygen isotopomers.

\section{Acknowledgements}

The author thanks many excellent coworkers and collaborators whose names appear in the references. Financial supports by KAKENHI from Japan Society for The Promotion of Science (JSPS) and from Ministry of Education, Culture, Sports, Science and Technology (MEXT) are gratefully acknowledged. Financial supports from New Energy and Industrial Technology Development Organization (NEDO) and from Japan Space Forum are also gratefully acknowledged.

\section{References}

1) Pasteur, L. (1848) Recherches sur les relations qui peuvent exister entre la forme crystalline, la composition chimique et le sens de la polarisation rotatoire. Ann. Chim. Phys. 24, 442-459.

2) Guijarro, A. and Yus, M. (2009) The Origin of Chirality in the Molecules of Life. The Royal Society of Chemistry, Cambridge.

3) Mislow, K. (2003) Absolute asymmetric synthesis: A commentary. Collect. Czech. Chem. Commun. 68, 849-864.

4) Feringa, B.L. and van Delden, R.A. (1999) Absolute asymmetric synthesis: The origin, control, and amplification of chirality. Angew. Chem. Int. Ed. 38, 3418-3438.

5) Inoue, Y. (1992) Asymmetric photochemical reactions in solution. Chem. Rev. 92, 741-770.

6) Hazen, R.M. and Sholl, D.S. (2003) Chiral selection on inorganic crystalline surfaces. Nat. Mater. 2, 367-374.

7) Bolli, M., Micura, R. and Eschenmoser, A. (1997) Pyranosyl-RNA: Chiroselective self-assembly of base sequences by ligative oligomerization of tetranucleotide- $2^{\prime}, 3^{\prime}$-cyclophosphates (with a commentary concerning the origin of biomolecular homochirality). Chem. Biol. 4, 309-320.

8) Ribó, J.M., Crusats, J., Sagués, F., Claret, J. and Rubires, R. (2001) Chiral sign induction by vortices during the formation of mesophases in 
stirred solutions. Science 292, 2063-2066.

9) Ernst, K.-H. (2012) Molecular chirality at surfaces. Phys. Status Solidi B 249, 2057-2088.

10) Weissbuch, I. and Lahav, M. (2011) Crystalline architectures as templates of relevance to the origins of homochirality. Chem. Rev. 111, 32363267.

11) Kitamura, M., Okada, S., Suga, S. and Noyori, R. (1989) Enantioselective addition of dialkylzincs to aldehydes promoted by chiral amino alcohols. Mechanism and nonlinear effect. J. Am. Chem. Soc. 111, 4028-4036.

12) Satyanarayana, T., Abraham, S. and Kagan, H.B. (2009) Nonlinear effects in asymmetric catalysis. Angew. Chem. Int. Ed. 48, 456-494.

13) Kondepudi, D.K. and Asakura, K. (2001) Chiral autocatalysis, spontaneous symmetry breaking, and stochastic behavior. Acc. Chem. Res. 34, 946-954.

14) Viedma, C. (2005) Chiral symmetry breaking during crystallization: Complete chiral purity induced by nonlinear autocatalysis and recycling. Phys. Rev. Lett. 94, 065504.

15) Soloshonok, V.A., Ueki, H., Yasumoto, M., Mekala, S., Hirschi, J.S. and Singleton, D.A. (2007) Phenomenon of optical self-purification of chiral non-racemic compounds. J. Am. Chem. Soc. 129, $12112-12113$

16) Hayashi, Y., Matsuzawa, M., Yamaguchi, J., Yonehara, S., Matsumoto, Y., Shoji, M. et al. (2006) Large nonlinear effect observed in the enantiomeric excess of proline in solution and that in the solid state. Angew. Chem. Int. Ed. 45, 4593-4597.

17) Córdova, A., Engqvist, M., Ibrahem, I., Casas, J. and Sundén, H. (2005) Plausible origins of homochirality in the amino acid catalyzed neogenesis of carbohydrates. Chem. Commun. (Camb.) 2047-2049.

18) Green, M.M., Park, J.-W., Sato, T., Teramoto, A. Lifson, S., Selinger, R.L.B. et al. (1999) The macromolecular route to chiral amplification. Angew. Chem. Int. Ed. 38, 3138-3154.

19) Noorduin, W.L., Vlieg, E., Kellogg, R.M. and Kaptein, B. (2009) From Ostwald ripening to single chirality. Angew. Chem. Int. Ed. 48, 96009606.

20) Saito, Y. and Hyuga, H. (2013) Colloquium: homochirality: Symmetry breaking in systems driven far from equilibrium. Rev. Mod. Phys. 85, 603-621.

21) Frank, F.C. (1953) On spontaneous asymmetric synthesis. Biochim. Biophys. Acta 11, 459-463.

22) Soai, K., Shibata, T., Morioka, H. and Choji, K. (1995) Asymmetric autocatalysis and amplification of enantiomeric excess of a chiral molecule. Nature 378, 767-768.

23) Shibata, T., Morioka, H., Hayase, T., Choji, K. and Soai, K. (1996) Highly enantioselective catalytic asymmetric automultiplication of chiral pyrimidyl alcohol. J. Am. Chem. Soc. 118, 471-472.

24) Shibata, T., Yonekubo, S. and Soai, K. (1999)
Practically perfect asymmetric autocatalysis using 2-alkynyl-5-pyrimidylalkanol. Angew. Chem. Int. Ed. 38, 659-661.

25) Sato, I., Urabe, H., Ishiguro, S., Shibata, T. and Soai, K. (2003) Amplification of chirality from extremely low to greater than $99.5 \%$ ee by asymmetric autocatalysis. Angew. Chem. Int. Ed. 42, 315-317.

26) Sato, I., Yanagi, T. and Soai, K. (2002) Highly enantioselective asymmetric autocatalysis of 2alkenyl- and 2-vinyl-5-pyrimidyl alkanols with significant amplification of enantiomeric excess. Chirality 14, 166-168.

27) Kawasaki, T., Nakaoda, M., Takahashi, Y., Kanto, Y., Kuruhara, N., Hosoi, K. et al. (2014) Selfreplication and amplification of enantiomeric excess of chiral multi-functionalized large molecule by asymmetric autocatalysis. Angew. Chem. Int. Ed. 53, 11199-11202.

28) Kawasaki, T., Ishikawa, Y., Minato, Y., Otsuka, T., Yonekubo, S., Sato, I. et al. (2017) Point-to-point ultra-remote asymmetric control with flexible linker. Chemistry 23, 282-285.

29) Shibata, T., Choji, K., Morioka, H., Hayase, T. and Soai, K. (1996) Highly enantioselective synthesis of a chiral 3-quinolylalkanol by an asymmetric autocatalytic reaction. Chem. Commun. (Camb.) 751-752.

30) Shibata, T., Choji, K., Hayase, T., Aizu, Y. and Soai, K. (1996) Asymmetric autocatalytic reaction of 3-quinolylalkanol with amplification of enantiomeric excess. Chem. Commun. (Camb.) 12351236.

31) Sato, I., Nakao, T., Sugie, R., Kawasaki, T. and Soai, K. (2004) Enantioselective synthesis of substituted 3-quinolyl alkanols and their application to asymmetric autocatalysis. Synthesis 14191428.

32) Shibata, T., Morioka, H., Tanji, S., Hayase, T., Kodaka, Y. and Soai, K. (1996) Enantioselective synthesis of chiral 5-carbamoyl-3-pyridyl alcohols by asymmetric autocatalytic reaction. Tetrahedron Lett. 37, 8783-8786.

33) Tanji, S., Kodaka, Y., Ohno, A., Shibata, T., Sato, I. and Soai, K. (2000) Asymmetric autocatalysis of 5-carbamoyl-3-pyridyl alkanols with amplification of enantiomeric excess. Tetrahedron Asymmetry 11, 4249-4253.

34) Soai, K. and Kawasaki, T. (2008) Asymmetric autocatalysis with amplification of chirality. Top. Curr. Chem. 284, 1-31.

35) Kawasaki, T. and Soai, K. (2011) Asymmetric induction arising from enantiomerically enriched carbon-13 isotopomers and highly sensitive chiral discrimination by asymmetric autocatalysis. Bull. Chem. Soc. Jpn. 84, 879-892.

36) Kawasaki, T. and Soai, K. (2012) Asymmetric autocatalysis triggered by chiral crystals formed from achiral compounds and chiral isotopomers. Isr. J. Chem. 52, 582-590.

37) Soai, K. and Kawasaki, T. (2012) Asymmetric autocatalysis - Discovery and state of the art - . 
In The Soai Reaction and Related Topic (eds. Pályi, G., Zucchi, C. and Caglioti, C.). Academia Nationale di Scienze Lettere e Arti Modena, Modena, Edizioni Artestampa, Modena, pp. 9-34.

38) Soai, K., Kawasaki, T. and Matsumoto, A. (2014) Asymmetric autocatalysis of pyrimidyl alkanol and its application to the study on the origin of homochirality. Acc. Chem. Res. 47, 3643-3654.

39) Podlech, J. and Gehring, T. (2005) New aspects of Soai's asymmetric autocatalysis. Angew. Chem. Int. Ed. 44, 5776-5777.

40) Caglitoti, L., Zucchi, C. and Pályi, G. (2005) Singlemolecule chirality. Chim. Oggi 38-39, 42-43.

41) Gehring, T., Busch, M., Schlageter, M. and Weingand, D. (2010) A concise summary of experimental facts about the Soai reaction. Chirality 22, E173-E182.

42) Soai, K. and Niwa, S. (1992) Enantioselective addition of organozinc reagents to aldehydes. Chem. Rev. 92, 833-856.

43) Noyori, R. and Kitamura, M. (1991) Enantioselective addition of organometallic reagents to carbonyl compounds: Chirality transfer, multiplication, and amplification. Angew. Chem. Int. Ed. Engl. 30, 49-69.

44) Soai, K., Hori, H. and Niwa, S. (1989) Enantioselective addition of dialkylzincs to pyridinecarbaldehyde in the presence of chiral aminoalcohols: Asymmetric synthesis of pyridylalkyl alcohols. Heterocycles 29, 2065-2067.

45) Soai, K., Yokoyama, S. and Hayasaka, T. (1991) Chiral $N, N$-dialkylnorephedrines as catalysts of the highly enantioselective addition of dialkylzincs to aliphatic and aromatic aldehydes. The asymmetric synthesis of secondary aliphatic and aromatic alcohols of high optical purity. J. Org. Chem. 56, 4264-4268.

46) Soai, K., Yokoyama, S., Ebihara, K. and Hayasaka, T. (1987) A new chiral catalyst for the highly enantioselective addition of dialkylzinc reagents to aliphatic aldehydes. J. Chem. Soc. Chem. Commun. 1690-1691.

47) Soai, K., Ookawa, A., Kaba, T. and Ogawa, K. (1987) Catalytic asymmetric induction. Highly enantioselective addition of dialkylzincs to aldehydes using chiral pyrrolidinylmethanols and their metal salts. J. Am. Chem. Soc. 109, 7111-7115.

48) Soai, K., Niwa, S. and Hori, H. (1990) Asymmetric self-catalytic reaction. Self-production of chiral 1(3-pyridyl)alkanols as chiral self-catalysts in the enantioselective addition of dialkylzinc reagents to pyridine-3-carbaldehyde. J. Chem. Soc. Chem. Commun. 982-983.

49) Sato, I., Omiya, D., Tsukiyama, K., Ogi, Y. and Soai, K. (2001) Evidence of asymmetric autocatalysis in the enantioselective addition of diisopropylzinc to pyrimidine-5-carbaldehyde using chiral pyrimidyl alkanol. Tetrahedron Asymmetry 12, 1965-1969.

50) Sato, I., Omiya, D., Igarashi, H., Kato, K., Ogi, Y., Tsukiyama, K. et al. (2003) Relationship between the time, yield, and enantiomeric excess of asymmetric autocatalysis of chiral 2-alkynyl-5pyrimidyl alkanol with amplification of enantiomeric excess. Tetrahedron Asymmetry 14, 975979.

51) Kitamura, M., Suga, S., Oka, H. and Noyori, R. (1998) Quantitative analysis of the chiral amplification in the amino alcohol-promoted asymmetric alkylation of aldehydes with dialkylzincs. J. Am. Chem. Soc. 120, 9800-9809.

52) Blackmond, D.G., McMillan, C.R., Ramdeehul, S., Schorm, A. and Brown, J.M. (2001) Origins of asymmetric amplification in autocatalytic alkylzinc additions. J. Am. Chem. Soc. 123, 1010310104 .

53) Quaranta, M., Gehring, T., Odell, B., Brown, J.M. and Blackmond, D.G. (2010) Unusual inverse temperature dependence on reaction rate in the asymmetric autocatalytic alkylation of pyrimidyl aldehydes. J. Am. Chem. Soc. 132, 15104-15107.

54) Gehring, T., Quaranta, M., Odell, B., Blackmond, D.G. and Brown, J.M. (2012) Observation of a transient intermediate in Soai's asymmetric autocatalysis: Insights from ${ }^{1} \mathrm{H}$ NMR turnover in real time. Angew. Chem. Int. Ed. 51, 9539-9542.

55) Schiaffino, L. and Ercolani, G. (2008) Unraveling the mechanism of the Soai asymmetric autocatalytic reaction by first-principles calculations: Induction and amplification of chirality by selfassembly of hexamolecular complexes. Angew. Chem. Int. Ed. 47, 6832-6835.

56) Ercolani, G. and Schiaffino, L. (2011) Putting the mechanism of the Soai reaction to the test: DFT study of the role of aldehyde and dialkylzinc structure. J. Org. Chem. 76, 2619-2626.

57) Gridnev, I.D. and Vorobiev, A.K. (2012) Quantification of sophisticated equilibria in the reaction pool and amplifying catalytic cycle of the Soai reaction. ACS Catal. 2, 2137-2149.

58) Barabás, B., Caglioti, L., Micskei, K. and Pályi, G. (2009) Data-based stochastic approach to absolute asymmetric synthesis by autocatalysis. Bull. Chem. Soc. Jpn. 82, 1372-1376.

59) Micheau, J.-C., Cruz, J.-M., Coudret, C. and Buhse, T. (2010) An autocatalytic cycle model of asymmetric amplification and mirror-symmetry breaking in the Soai reaction. ChemPhysChem 11, 3417-3419.

60) Lavabre, D., Micheau, J.-C., Islas, J.R. and Buhse, T. (2008) Kinetic insight into specific features of the Autocatalytic Soai reaction. Top. Curr. Chem. 284, 67-96.

61) Micskei, K., Rábai, G., Gál, E., Caglioti, L. and Pályi, G. (2008) Oscillatory symmetry breaking in the Soai reaction. J. Phys. Chem. B 112, 91969200 .

62) Maioli, M., Micskei, K., Caglioti, L., Zucchi, C. and Pályi, G. (2008) Evolution of chirality in consecutive asymmetric autocatalytic reaction cycles. J. Math. Chem. 43, 1505-1515.

63) Crusats, J., Hochberg, D., Moyano, A. and Ribó, J.M. (2009) Frank model and spontaneous emergence of chirality in closed systems. 
ChemPhysChem 10, 2123-2131.

64) Dóka, É. and Lente, G. (2011) Mechanism-based chemical understanding of chiral symmetry breaking in the Soai reaction. A combined probabilistic and deterministic description of chemical reactions. J. Am. Chem. Soc. 133, $17878-17881$

65) Micheau, J.-C., Coudret, C., Cruz, J.-M. and Buhse, T. (2012) Amplification of enantiomeric excess, mirror-image symmetry breaking and kinetic proofreading in Soai reaction models with different oligomeric orders. Phys. Chem. Chem. Phys. 214, 13239-13248.

66) Matsumoto, A., Abe, T., Hara, A., Tobita, T., Sasagawa, T.T., Kawasaki, T. et al. (2015) Crystal structure of isopropylzinc alkoxide of pyrimidyl alkanol: Mechanistic insights for asymmetric autocatalysis with amplification of enantiomeric excess. Angew. Chem. Int. Ed. 54, $15218-15221$

67) Matsumoto, A., Fujiwara, S., Abe, T., Hara, A., Tobita, T., Sasagawa, T. et al. (2016) Elucidation of the structures of asymmetric autocatalyst based on X-ray crystallography. Bull. Chem. Soc. Jpn. 89, 1170-1177.

68) Gridnev, I.D. and Vorobiev, A.K. (2015) On the origin and structure of the recently observed acetal in the Soai reaction. Bull. Chem. Soc. Jpn. 88, 333-340.

69) Noble-Teran, M.E., Cruz, J.-M., Micheau, J.-C. and Buhse, T.W. (2018) A quantification of the Soai reaction. ChemCatChem 10, 642-648.

70) Bailey, J., Chrysostomou, A., Hough, J.H., Gledhill, T.M., McCall, A., Clark, S. et al. (1998) Circular polarization in star-formation regions: Implications for biomolecular homochirality. Science 281, $672-674$.

71) Shibata, T., Yamamoto, J., Matsumoto, N., Yonekubo, S., Osanai, S. and Soai, K. (1998) Amplification of a slight enantiomeric imbalance in molecules based on asymmetric autocatalysis. - The first correlation between high enantiomeric enrichment in a chiral molecule and circularly polarized light—. J. Am. Chem. Soc. 120, 1215712158.

72) Kawasaki, T., Sato, M., Ishiguro, S., Saito, T., Morishita, Y., Sato, I. et al. (2005) Enantioselective synthesis of near enantiopure compound by asymmetric autocatalysis triggered by asymmetric photolysis with circularly polarized light. J. Am. Chem. Soc. 127, 3274-3275.

73) Sato, I., Sugie, R., Matsueda, Y., Furumura, Y. and Soai, K. (2004) Asymmetric synthesis utilizing circularly polarized light mediated by the photoequilibrium of chiral olefins in conjunction with asymmetric autocatalysis. Angew. Chem. Int. Ed. 43, 4490-4492.

74) Soai, K., Osanai, S., Kadowaki, K., Yonekubo, S., Shibata, T. and Sato, I. (1999) $d$ - and $l$-Quartzpromoted highly enantioselective synthesis of a chiral organic compound. J. Am. Chem. Soc. 121, 11235-11236.
75) Sato, I., Kadowaki, K. and Soai, K. (2000) Asymmetric synthesis of an organic compound with high enantiomeric excess induced by inorganic ionic sodium chlorate. Angew. Chem. Int. Ed. 39, 1510-1512.

76) Sato, I., Kadowaki, K., Ohgo, Y. and Soai, K. (2004) Highly enantioselective asymmetric autocatalysis induced by chiral ionic crystals of sodium chlorate and sodium bromate. J. Mol. Catal. A Chem. 216 , 209-214.

77) Shindo, H., Shirota, Y., Niki, K., Kawasaki, T., Suzuki, K., Araki, Y. et al. (2013) Asymmetric autocatalysis induced by cinnabar: Observation of the enantioselective adsorption of a 5-pyrimidyl alkanol on the crystal surface. Angew. Chem. Int. Ed. 52, 9135-9138.

78) Matsumoto, A., Ozawa, H., Inumaru, A. and Soai, K. (2015) Asymmetric induction by retgersite, nickel sulfate hexahydrate, in conjunction with asymmetric autocatalysis. New J. Chem. 39, 6742-6745.

79) Matsumoto, A., Kaimori, Y., Uchida, M., Omori, H., Kawasaki, T. and Soai, K. (2017) Achiral inorganic gypsum acts as an origin of chirality through its enaniotopic surface in conjunction with asymmetric autocatalysis. Angew. Chem. Int. Ed. 56, 545-548.

80) Kawasaki, T., Suzuki, K., Hakoda, Y. and Soai, K. (2008) Achiral nucleobase cytosine acts as an origin of homochirality of biomolecules in conjunction with asymmetric autocatalysis. Angew. Chem. Int. Ed. 47, 496-499.

81) Kawasaki, T., Hakoda, Y., Mineki, H., Suzuki, K. and Soai, K. (2010) Generation of absolute controlled crystal chirality by the removal of crystal water from achiral crystal of nucleobase cytosine. J. Am. Chem. Soc. 132, 2874-2875.

82) Mineki, H., Kaimori, Y., Kawasaki, T., Matsumoto, A. and Soai, K. (2013) Enantiodivergent formation of a chiral cytosine crystal by removal of crystal water from an achiral monohydrate crystal under reduced pressure. Tetrahedron Asymmetry 24, 1365-1367.

83) Mineki, H., Hanasaki, T., Matsumoto, A., Kawasaki, T. and Soai, K. (2012) Asymmetric autocatalysis initiated by achiral nucleic acid base adenine: Implications on the origin of homochirality of biomolecules. Chem. Commun. (Camb.) 48, 10538-10540.

84) Kawasaki, T., Suzuki, K., Hatase, K., Otsuka, M., Koshima, H. and Soai, K. (2006) Enantioselective synthesis mediated by chiral crystal of achiral hippuric acid in conjunction with asymmetric autocatalysis. Chem. Commun. (Camb.) 18691871.

85) Carter, D.J., Rohl, A.L., Shtukenberg, A., Bian, S.D., Hu, C.-H., Baylon, L. et al. (2012) Prediction of Soai reaction enantioselectivity induced by crystals of $N$-(2-thienylcarbonyl)glycine. Cryst. Growth Des. 12, 2138-2145.

86) Kawasaki, T., Jo, K., Igarashi, H., Sato, I., Nagano, M., Koshima, H. et al. (2005) Asymmetric 
amplification using chiral co-crystal formed from achiral organic molecules by asymmetric autocatalysis. Angew. Chem. Int. Ed. 44, 2774-2777.

87) Kawasaki, T., Harada, Y., Suzuki, K., Tobita, T., Florini, N., Palyi, G. et al. (2008) Enantioselective synthesis utilizing enantiomorphous organic crystal of achiral benzils as a source of chirality in asymmetric autocatalysis. Org. Lett. 10, 40854088.

88) Kawasaki, T., Nakaoda, M., Kaito, N., Sasagawa, T. and Soai, K. (2010) Asymmetric autocatalysis induced by chiral crystals of achiral tetraphenylethylenes. Orig. Life Evol. Biosph. 40, 65-78.

89) Matsumoto, A., Ide, T., Kaimori, Y., Fujiwara, S. and Soai, K. (2015) Asymmetric autocatalysis triggered by chiral crystal of achiral ethylenediamine sulfate. Chem. Lett. 44, 688-690.

90) Kawasaki, T., Uchida, M., Kaimori, Y., Sasagawa, T., Matsumoto, A. and Soai, K. (2013) Enantioselective synthesis induced by the helical molecular arrangement in the chiral crystal of achiral tris(2-hydroxyethyl)-1,3,5-benzenetricarboxylate in conjunction with asymmetric autocatalysis. Chem. Lett. 42, 711-713.

91) Matsumoto, A., Takeda, S., Harada, S. and Soai, K. (2016) Determination of the absolute structure of the chiral crystal consisting of achiral dibutylhydroxytoluene and asymmetric autocatalysis triggered by this chiral crystal. Tetrahedron Asymmetry 27, 943-946.

92) Kawasaki, T., Sasagawa, T., Shiozawa, K., Uchida, M., Suzuki, K. and Soai, K. (2011) Enantioselective synthesis induced by chiral crystal composed of DL-serine in conjunction with asymmetric autocatalysis. Org. Lett. 13, 2361-2363.

93) Kawasaki, T., Kamimura, S., Amihara, A., Suzuki, K. and Soai, K. (2011) Enantioselective C-C bond formation as a result of the oriented prochirality of an achiral aldehyde at the single-crystal face upon treatment with a dialkylzinc vapor. Angew. Chem. Int. Ed. 50, 6796-6798.

94) Caglioti, L., Hajdu, C., Holczknecht, O., Zékány, L., Zucchi, C., Micskei, K. et al. (2006) The concept of racemates and the Soai-reaction. Viva Orig. 34, $62-80$.

95) Maioli, M., Varadi, G., Kurdi, R., Caglioti, L. and Palyi, G. (2016) Limits of the classical concept of concentration. J. Phys. Chem. B 120, 7438-7445.

96) Soai, K., Sato, I., Shibata, T., Komiya, S., Hayashi, M., Matsueda, Y. et al. (2003) Asymmetric synthesis of pyrimidyl alkanol without adding chiral substances by the addition of diisopropylzinc to pyrimidine-5-carbaldehyde in conjunction with asymmetric autocatalysis. Tetrahedron Asymmetry 14, 185-188.

97) Soai, K., Shibata, T. and Kowata, Y. (1997) Production of optically active pyrimidylalkyl alcohol by spontaneous asymmetric synthesis. Jpn. Kokai Tokkyo Koho JP HP09-268179. 1997-10-14 (priority date; 1996-02-01). An abstract is readily available as JPH09268179 from the European Patent Office (Espacenet).
98) Kawasaki, T., Suzuki, K., Shimizu, M., Ishikawa, K. and Soai, K. (2006) Spontaneous absolute asymmetric synthesis in the presence of achiral silica gel in conjunction with asymmetric autocatalysis. Chirality 18, 479-482.

99) Suzuki, K., Hatase, K., Nishiyama, D., Kawasaki, T. and Soai, K. (2010) Spontaneous absolute asymmetric synthesis promoted by achiral amines in conjunction with asymmetric autocatalysis. J. Syst. Chem. 1, 5.

100) Singleton, D.A. and Vo, L.K. (2003) A few molecules can control the enantiomeric outcome. Evidence supporting absolute asymmetric synthesis using the Soai asymmetric autocatalysis. Org. Lett. 5, 4337-4339.

101) Kawasaki, T., Shimizu, M., Nishiyama, D., Ito, M., Ozawa, H. and Soai, K. (2009) Asymmetric autocatalysis induced by meteoritic amino acids with hydrogen isotope chirality. Chem. Commun. (Camb.) 4396-4398.

102) Sato, I., Omiya, D., Saito, T. and Soai, K. (2000) Highly enantioselective synthesis induced by chiral primary alcohols due to deuterium substitution. J. Am. Chem. Soc. 122, 11739-11740.

103) Kawasaki, T., Ozawa, H., Ito, M. and Soai, K. (2011) Enantioselective synthesis induced by compounds with chirality arising from partially deuterated methyl groups in conjunction with asymmetric autocatalysis. Chem. Lett. 40, 320321.

104) Kawasaki, T., Matsumura, Y., Tsutsumi, T., Suzuki, K., Ito, M. and Soai, K. (2009) Asymmetric autocatalysis triggered by carbon isotope $\left({ }^{13} \mathrm{C} /{ }^{12} \mathrm{C}\right)$ chirality. Science 324, 492-495.

105) Matsumoto, A., Ozaki, H., Harada, S., Tada, K., Ayugase, T., Ozawa, H. et al. (2016) Asymmetric induction by nitrogen ${ }^{14} \mathrm{~N} /{ }^{15} \mathrm{~N}$ isotopomer in conjunction with asymmetric autocatalysis. Angew. Chem. Int. Ed. 55, 15246-15249.

106) Kawasaki, T., Okano, Y., Suzuki, E., Takano, S., Oji, S. and Soai, K. (2011) Asymmetric autocatalysis: Triggered by chiral isotopomer arising from oxygen isotope substitution. Angew. Chem. Int. Ed. 50, 8131-8133.

107) Matsumoto, A., Oji, S., Takano, S., Tada, K., Kawasaki, T. and Soai, K. (2013) Asymmetric autocatalysis triggered by oxygen isotopically chiral glycerin. Org. Biomol. Chem. 11, 29282931.

108) Barabás, B., Caglioti, L., Micskei, K. and Palyi, G. (2008) Isotope chirality and asymmetric autocatalysis: A possible entry to biological chirality. Orig. Life Evol. Biosph. 38, 317-327.

109) Barabás, B., Kurdi, R., Zucchi, C. and Palyi, G. (2018) Isotope chirality in long-armed multifunctional organosilicon ("Cephalopod") molecules. Chirality 30, 913-922.

110) Sato, I., Ohgo, Y., Igarashi, H., Nishiyama, D., Kawasaki, T. and Soai, K. (2007) Determination of absolute configurations of amino acids by asymmetric autocatalysis of 2-alkynylpyrimidyl alkanol as a chiral sensor. J. Organomet. Chem. 
692, 1783-1787.

111) Kawasaki, T., Hatase, K., Fujii, Y., Jo, K., Soai, K. and Pizzarello, S. (2006) The distribution of chiral asymmetry in meteorites: An investigation using asymmetric autocatalytic chiral sensors. Geochim. Cosmochim. Acta 70, 5395-5402.

112) Kawasaki, T., Tanaka, H., Tsutsumi, T., Kasahara, T., Sato, I. and Soai, K. (2006) Chiral discrimination of cryptochiral saturated quaternary and tertiary hydrocarbons by asymmetric autocatalysis. J. Am. Chem. Soc. 128, 6032-6033.

113) Kawasaki, T., Hohberger, C., Araki, Y., Hatase, K., Beckerle, K., Okuda, J. et al. (2009) Discrimination of cryptochirality in chiral isotactic polystyrene by asymmetric autocatalysis. Chem. Commun. (Camb.) 5621-5623.

114) Sato, I., Yamashima, R., Kadowaki, K., Yamamoto, J., Shibata, T. and Soai, K. (2001) Asymmetric induction by helical hydrocarbons: [6]- and [5]helicenes. Angew. Chem. Int. Ed. 40, 10961098.

115) Kawasaki, T., Suzuki, K., Licandro, E., Bossi, A., Maiorana, S. and Soai, K. (2006) Enantioselective synthesis induced by tetrathia-[7]-helicenes in conjunction with asymmetric autocatalysis. Tetrahedron Asymmetry 17, 2050-2053.

116) Matsumoto, A., Yonemitsu, K., Ozaki, H., Míšek, J., Starý, I., Stará, I.G. et al. (2017) Reversal of the sense of enantioselectivity between 1 - and 2aza[6]helicenes used as chiral inducers of asymmetric autocatalysis. Org. Biomol. Chem. 15, 1321-1324.

117) Sato, I., Kadowaki, K., Urabe, H., Hwa Jung, J., Ono, Y., Shinkai, S. et al. (2003) Highly enantioselective synthesis of organic compound using right- and left-handed helical silica. Tetrahedron
Lett. 44, 721-724.

118) Kawasaki, T., Araki, Y., Hatase, K., Suzuki, K., Matsumoto, A., Yokoi, T. et al. (2015) Helical mesoporous silica as an inorganic heterogeneous chiral trigger for asymmetric autocatalysis with amplification of enantiomeric excess. Chem. Commun. (Camb.) 51, 8742-8744.

119) Lutz, F., Igarashi, T., Kawasaki, T. and Soai, K. (2005) Small amounts of achiral $\beta$-amino alcohols reverse the enantioselectivity of chiral catalysts in cooperative asymmetric autocatalysis. J. Am. Chem. Soc. 127, 12206-12207.

120) Lutz, F., Igarashi, T., Kinoshita, T., Asahina, M., Tsukiyama, K., Kawasaki, T. et al. (2008) Mechanistic insights in the reversal of enantioselectivity of chiral catalysts by achiral catalysts in asymmetric autocatalysis. J. Am. Chem. Soc. 130, 2956-2958.

121) Matsumoto, A., Fujiwara, S., Hiyoshi, Y., Zawatzky, K., Makarov, A.A., Welch, C.J. et al. (2017) Unusual reversal of enantioselectivity in the asymmetric autocatalysis of pyrimidyl alkanol triggered by chiral aromatic alkanols and amines. Org. Biomol. Chem. 15, 555-558.

122) Sato, I., Urabe, H., Ishii, S., Tanji, S. and Soai, K. (2001) Asymmetric synthesis with a chiral catalyst generated from asymmetric autocatalysis. Org. Lett. 3, 3851-3854.

123) Funes-Maldonado, M., Sieng, B. and Amedjkouh, M. (2016) Asymmetric autocatalysis as a relay for remote amplification of chirality of target molecules used as triggers. Org. Lett. 18, 2536-2539.

(Received Nov. 23, 2018; accepted Dec. 18, 2018) 


\section{Profile}

Kenso Soai was born in 1950 in Hiroshima, Japan. He obtained his B.S. degree from the University of Tokyo in 1974 and his Ph.D. degree in 1979 from the University of Tokyo under the supervision of Professor Teruaki Mukaiyama. He was JSPS Fellow and was a postdoctoral research associate with Professor Ernest L. Eliel at the University of North Carolina at Chapel Hill. He joined the faculty of Tokyo University of Science in 1981 as a Lecturer (PI). He was promoted to Associate Professor in 1986 and to Professor in 1991. He is an honorary member of National Academy of Sciences, Letters and Arts, Modena (Italy) and received Doctor Honoris Causa from University of Pannonia (Hungary). He was Visiting Professor at Ecole Supérieure de Physique et Chimie Industrielles de la Ville de Paris (ESPCI) in 2001, Kyushu University in 2005, Waseda

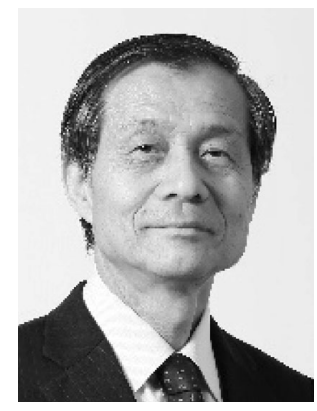
University in 2007-2010, Université Louis Pasteur (University of Strasbourg) in 2008 and Jilin University in 20102015. His research interests include asymmetric autocatalysis, the origin of homochirality, asymmetric catalysis and new synthetic method. His awards include Progress Award in Synthetic Organic Chemistry for 1988, Chisso Award in Synthetic Organic Chemistry for 1990, the Chemical Society of Japan Award for Creative Work for 1999, Inoue Prize for Science for 2000, Molecular Chirality Award for 2002, Merit of Science and Technology of Tokyo Metropolitan (2002), Synthetic Organic Chemistry Award for 2003, Medal of National Academy of Sciences, Letters and Arts, Modena (Italy, 2003), Chirality Medal for 2005, Novartis Lecturer at ETH Zurich (2006), Prize for Science and Technology by the Minister of Education, Culture, Sports, Science and Technology for 2007, the Chemical Society of Japan Award for 2010, Medal of Honor with Purple Ribbon for 2012 and Toray Science and Technology Award for 2017. 